\title{
Effect of Soil-Type and Fines Content on Liquefaction Resistance-Shear-Wave Velocity Correlation
}

\author{
Nurhan Ecemis \\ Civil Engineering Department, Izmir Inst Technol, Civil Engineering, Izmir Institute of Technology, Izmir, \\ Turkey
}

\begin{abstract}
Direct measurement of shear-wave velocity, $\mathrm{V}_{\mathrm{s}}$, in the field to evaluate the liquefaction resistance of soils is an alternative or complement approach to penetration-based methods. However, the existing liquefaction assessment methods established on the $\mathrm{V}_{\mathrm{s}}$ have uncertainties about how the fines content and soil-type change the relationship between $\mathrm{V}_{\mathrm{s}}$ and liquefaction resistance. The first part of this paper discusses the existence of fines on the correlation between cone penetration resistance and $\mathrm{V}_{\mathrm{s}}$. The second part focuses on the liquefaction resistance that is construed over again using the simplified cone penetration test (CPT)-based liquefaction screening procedure in terms of $\mathrm{V}_{\mathrm{s}}$ for three distinct ranges of non-/low plastic fines content $<35 \%$ fines. The outcomes of the investigation indicate that for each fines content, the correlation between CRR and $V_{s 1}$ is not unique; there is a significant scattering of the curves for different soil types. Finally, using the results of this investigation as well as the simplified CPT-based liquefaction screening method, a soil-type specific $C R R-V_{s 1}$ relationship developed for the unbounded, very young (Holocene-age) soils.
\end{abstract}

\section{ARTICLE HISTORY}

Received 17 August 2017

Accepted 29 April 2018

\section{KEYWORDS}

Liquefaction resistance; shear-wave velocity; sand with fines; CPT-based soil type; cone penetration resistance

\section{Introduction}

Liquefaction potential assessment is a complex phenomenon depending on several factors of soils such as void redistribution, fabric (deposition method), stress history, aging, effective confining stress, and shape and size distribution of particles. Since the simplified procedure of Seed and Idriss [1971], several in-situ tests are developed for the direct assessment of the liquefaction potential of sandy soils. These in-situ tests include the standard penetration test (SPT), cone penetration test (CPT), and shear-wave velocity $\left(V_{\mathrm{s}}\right)$ measurements [Youd et al., 2001]. None of the above-mentioned tests adequately reflect all factors affecting liquefaction resistance. For example, as noted by several researchers [e.g., Schmertmann, 1984; Marchetti, 2010], SPT and CPT tests mobilize large-strain measurements and are less sensitive to cementation and aging effects. In contrast, the measurement of $V_{\mathrm{s}}$ directly in the field is a small-strain measurement (strain level less than about $10^{-4} \%$ ) and is sensitive to cementation and aging effects [Andrus et al., 2004; El-Sekelly et al., 2016]. On the other hand, $V_{\mathrm{s}}$ does not reflect the critical friction angle

CONTACT Nurhan Ecemis nurhanecemis@iyte.edu.tr 0 Civil Engineering Department, Izmir Inst Technol, Civil Engineering, Izmir Institute of Technology, Izmir, Turkey.

Color versions of one or more of the figures in the article can be found online at www.tandfonline.com/ueqe. 
and dilatancy of the soil, both of which are known to affect liquefaction resistance (Salgado et al., 2000]. Nowadays, the $V_{\mathrm{s}}$ measurements to evaluate the liquefaction resistance of soils have obtained considerable relevance compared to penetration tests, because several investigations have shown that $V_{\mathrm{s}}$ and liquefaction resistance of soils are both susceptible the same factors such as relative density, effective stress state, rearrangement of particles with time and cementation in the same direction [Tokimatsu and Uchida, 1990; De Alba et al., 1994; Baxter et al., 2008]. Furthermore, $V_{\mathrm{s}}$ is a fundamental nondestructive parameter of soil that can be measured using laboratory and field tests with new techniques and low cost [Andrus et al., 2004; Kayen et al., 2013].

Since the beginning of the 1980s, numerous investigators have developed different correlations for $V_{\mathrm{s}}$-magnitude-dependent liquefaction resistance characterization. Initially, Seed et al. [1983] proposed a CRR- $V_{\mathrm{s} 1}$ (cyclic resistance ratio-overburden stress normalized $V_{\mathrm{s}}$ ) curve throughout SPT- $V_{\mathrm{s}}$ correlations. In the early $1990 \mathrm{~s}$, several CRR- $V_{\mathrm{s} 1}$ correlations proposed by direct measurement of $V_{s}$ at liquefied sites [e.g., Robertson et al., 1992; Lodge, 1994]. In 2000s, Juang et al. [2002], Moss et al. [2006], and Kayen et al. [2013] used probabilistic and deterministic methods for CRR- $V_{\mathrm{s} 1}$ correlation. Andrus and Stokoe [2000] created a chart from the liquefied and the non-liquefied sites and $V_{\mathrm{s}}$ measurements at many uncemented soils ranging from fine sand to sandy gravel of Holocene-age. The curves proposed by Andrus and Stokoe [2000] have been used as a final accepted $V_{\mathrm{s}}$-based liquefaction assessment chart that is used to determine the cyclic resistance ratio, with a given value of $V_{\text {s1 }}$ [Youd et al., 2001]. They proposed three boundary curves corresponding to the average fines content (FC) by mass of FC $\leq 5 \%, F C=20 \%$, and FC $\geq 35 \%$. Similar to the trends observed in the SPT and CPT-based CRR correlations at a given $V_{\mathrm{s} 1}$, CRR increases with increasing FC up to $35 \%$. At FC greater than $35 \%$, the $\mathrm{CRR}-V_{\mathrm{s} 1}$ relationship is assumed to remain constant. The existence of fines on $V_{\mathrm{s}}$-based liquefaction assessment is not well understood, and studies on the effects of fines on $V_{\mathrm{s}}$ have rarely been reported. Moreover, several researchers developed laboratory-based correlations using cyclic triaxial tests with bender elements [e.g., Tokimatsu et al., 1986; Baxter et al., 2008; Ahmadi and Paydar, 2014]. Some of the existing $V_{s 1}$-based liquefaction assessment curves are shown in Fig. 1. These existing $V_{\mathrm{s}}$-based liquefaction assessment methods display that for each $\mathrm{FC}$, the relationship between liquefaction resistance and $V_{\mathrm{s}}$ is not unique.

So far, many cone penetration $-V_{s}$ correlations have been proposed for different types of soils [e.g., Baldi et al., 1989; Rix and Stokoe, 1991; Robertson et al., 1992; Fear and Robertson, 1995; Hegazy and Mayne, 1995; Andrus et al., 2004; Andrus et al., 2007; Robertson, 2009; Karray et al., 2011; Cai et al., 2014]. If these existing soil specific $q_{\mathrm{c} 1 N^{-}}$ $V_{s 1}$ correlations are combined with the current field-based CPT-liquefaction assessment method [Robertson and Wride, 1998], several different CPT-based CRR- $V_{s 1}$ curves can be developed. For soils of similar geological origin, age, FC and $V_{s}$, the reason to obtain different liquefaction resistance may be due to the differences in the soil types. Recently, several investigators have studied to evaluate the soil-type specific correlation between liquefaction resistance and $V_{\mathrm{s}}$ of sand and silts by laboratory tests [Zhou and Chen, 2007; Baxter et al., 2008; Zhou et al., 2010; Ahmadi and Paydar, 2014].

Within the recent research projects TUBITAK-110M602 [Ecemis, 2013], and EU-Marie Curie IRG-248218 [Ecemis, 2014] a set of three field tests [piezocone penetration test (CPTu), seismic cone penetration tests (SCPTs), and SPT] that were performed side by side at 13 different locations on the northern coast of the Izmir Gulf in Turkey. For soil 


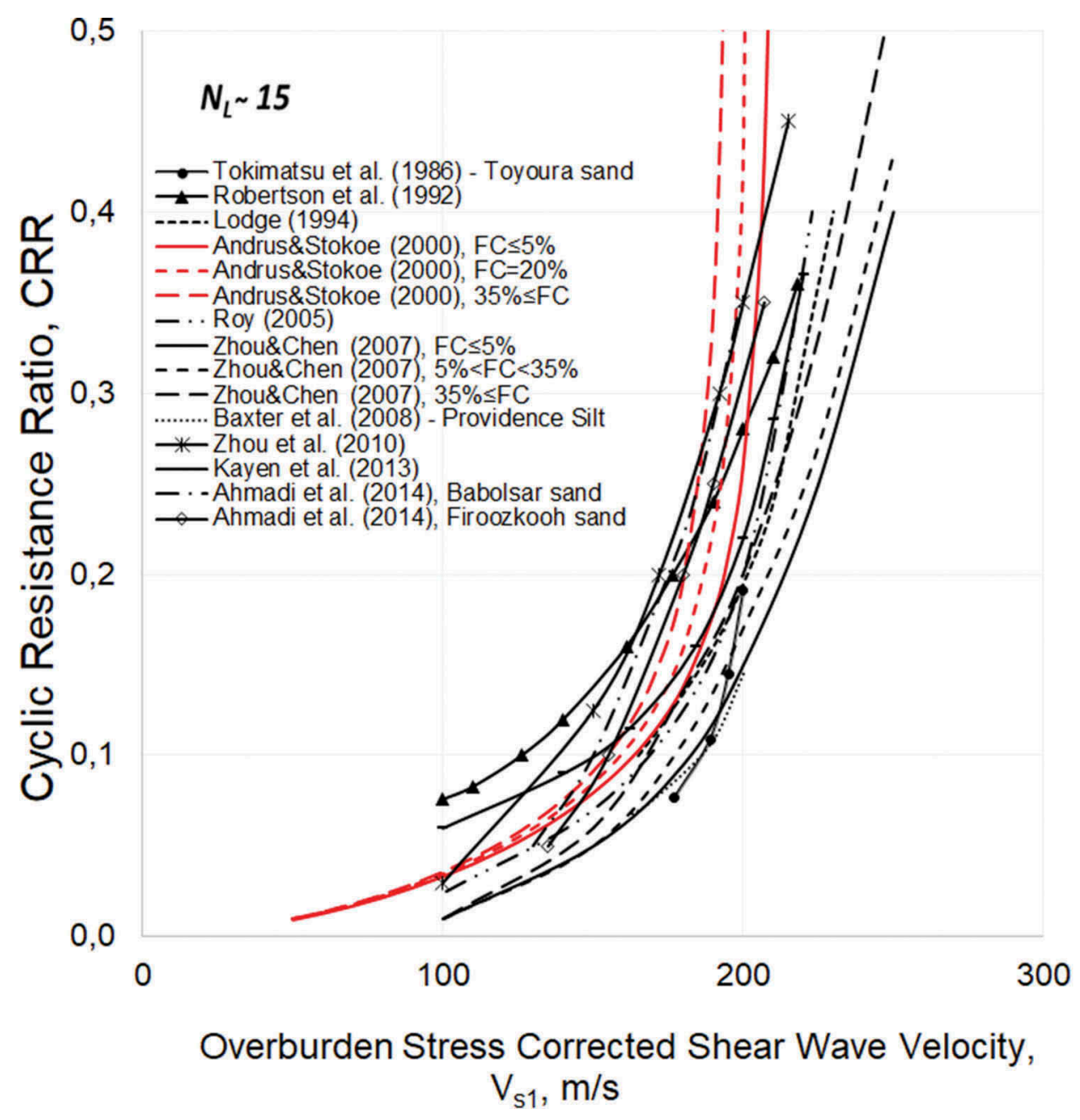

Figure 1 Existing shear-wave velocity-based liquefaction assessment curves for different soils.

characterization, disturbed samples were extracted from the boreholes using the SPT spoon. Shear-wave velocities were measured from the SCPTs, and cone penetration resistance of the soils was determined from the $\mathrm{CPTu}$ data. The field- and laboratorytest results were used to clarify (1) how FC affect $V_{\mathrm{s} 1}-q_{\mathrm{c} 1 N}$ correlation, (2) a soil-specific relation between $V_{s}$ and cone penetration resistance, and (3) how fines and soil-type affect the correlation between $V_{\mathrm{s}}$ and liquefaction resistance that is construed over again from the current CPT-based liquefaction assessment method proposed by Robertson and Wride [1998]. Finally, the soil-type specific correlation between overburden stress corrected $V_{\mathrm{s}}$ and liquefaction resistance to cause liquefaction is developed for the unbounded, very young (Holocene-age) soils. The established CRR- $V_{s 1}$ curves, based on soil type, are compared with the existing $V_{\mathrm{s}}$-based liquefaction assessment curves of several previous researchers. Detailed comparisons show that a soil-type specific CRR- $V_{\mathrm{s} 1}$ curve is a reliable prediction for site-specific investigations. 


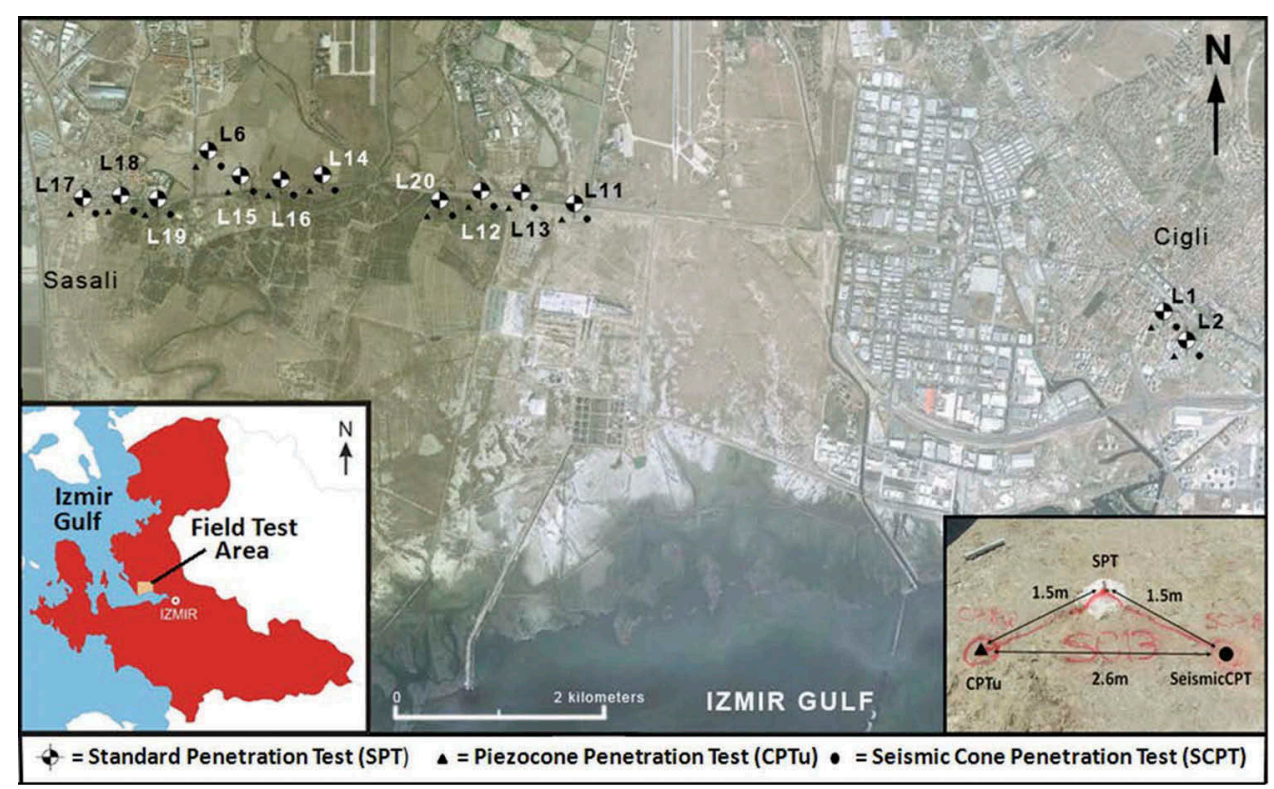

Figure 2 Area view of test profile locations on the northern coast of Izmir Gulf in Turkey.

\section{In-Situ Testing}

A set of three high-quality in-situ tests were conducted side by side at 13 different sites located on the northern coast of the Izmir Gulf [Ecemis, 2013; Ecemis, 2014]. Figure 2 shows the area view of performed CPTu, SCPT, and SPT locations. As shown in the figure, the three in-situ tests listed above were conducted in proximity at each location, to minimize the differences in stratigraphy. The total sounding depth for each test was about $15 \mathrm{~m}$. The field- and laboratory-test data were reported and analyzed at recent research projects TUBITAK-110M602 [Ecemis, 2013], EU-Marie Curie IRG-248218 [Ecemis, 2014], and Ecemis and Mustafa [2014] and thus only a brief summary is presented herein.

\subsection{Soil-Type and Fines Content in the Experimental Site}

The study site was carefully selected from the knowledge of the local geology preserved in the RADIUS project [1999] and by considering the following criteria: (1) sandy soils must mostly contain $0-35 \%$ non-/low plastic FC, given that FC over $30 \%$ by weight and/or high plasticity of fines is known to affect liquefaction resistance of fines containing sands. (2) The groundwater level should be high enough to ensure that the data would be obtained under fully saturated conditions. Based on the RADIUS project [1999], the surficial geology of the study area is predominantly composed of quaternary sediments. These sediments are mainly saturated and are formed by sedimentation of the alluvial fan deposits transported by the Gediz River. Geologic age of the deposits was Holocene-age (deposited $<10,000$ years before present day).

In order to define the FC range of the soil in the site, $45-\mathrm{cm}$-long disturbed soil samples were procured from the SPT spoon at approximately 1.5-m intervals. A total of 107 
disturbed soil samples have been collected at 13 different locations. The first $15 \mathrm{~cm}$ of the split spoon sample was typically disregarded because of soil disturbance. A useful portion of the soil sample (30-cm long) from the SPT spoon was mixed and used to conduct the sieve analysis test (ASTM D6913-04), hydrometer test (ASTM D422-63), and plastic limit tests (ASTM D4318-10). By using the Unified Soil Classification System (USCS), the majority of the soil type in the site classified as non-plastic poorly graded clean sand (SP) to silty sand (SM) with FC $<35 \%$. In addition, relatively small interbedded layers of silt mixtures and clays were encountered in the site. Figure $3 a$ shows grain size distribution curves of the soils from the field. As revealed from the figure, a total of 84 disturbed soil samples collected $<20 \%$ FC, and 23 disturbed soil samples collected from $20 \%$ to $35 \%$ FC. The mean grain size $\left(D_{50}\right)$ range from $0.1 \mathrm{~mm}$ to $0.35 \mathrm{~mm}$, and uniformity coefficient $\left(C_{\mathrm{u}}\right)$ change from 1.18 to 3.56 . Figure $3 \mathrm{~b}$ exemplifies the scanning electron microscope (SEM) image of the angular sand grains and fine particles from the site. The abovementioned in-situ tests and study area offered a test bed opportunity to examine the influence of soil type and FC on liquefaction resistance-shear wave velocity correlation.

\subsection{Cone Penetration Resistance}

All cone penetration resistance $\left(q_{\mathrm{c}}\right)$ of the soils were recorded from the CPTu's that were conducted by using the classic CPTu probe, which has $60^{\circ}$ tip angle and $10 \mathrm{~cm}^{2}$ tip area. $\mathrm{CPTu}$ soundings were performed using a truck with a pushing capacity of $200 \mathrm{kN}$, with a constant penetration speed of $20 \mathrm{~mm} / \mathrm{s}$ (ASTM D3441). The independent measured parameters, for each $1 \mathrm{~cm}$ of penetration, are cone penetration resistance $q \mathrm{c}$, friction resistance $f \mathrm{~s}$, and pore water pressures above the cone face. The measured data were digitized inside the probe and then transferred acoustically (without a cable down the hole) to the data acquisition system on the ground surface. Total $13 \mathrm{CPTu}$ profiles were obtained in the experiment site where cone resistance values varied from about 1-9.5 MPa. To exemplify, Fig. 4a-b display the $q_{\mathrm{c}}$ and $f_{\mathrm{s}}$ profiles obtained from location L16 where the minimum and maximum cone resistance values measured about 2 and $9.5 \mathrm{MPa}$.

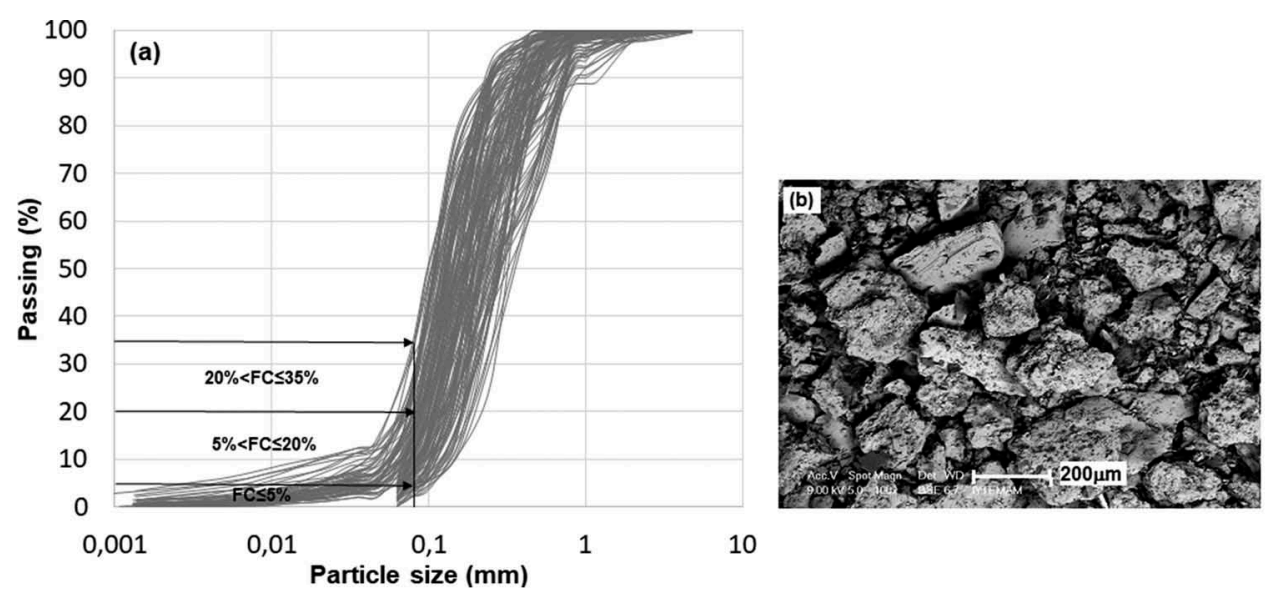

Figure 3 (a) Typical grain size distribution curves and (b) scanning electron micrograph of the silty sand in the experiment site. 
(a)

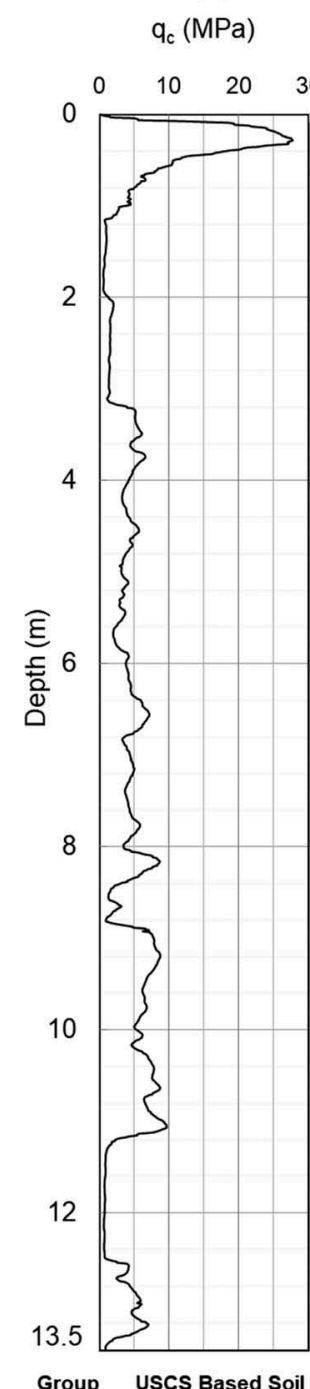

Group USCS Based Soil Type

SP Poorly Graded Sand

SM Silty Sand

SC Clayey Sand

SP-SM Sand, and Silty Sand Mixture

SP-SC Sand, Clayey Sand Mixture (c)

$\mathrm{f}_{\mathrm{s}}$ (MPa)

$\mathrm{V}_{\mathrm{s}}(\mathrm{m} / \mathrm{s})$

0
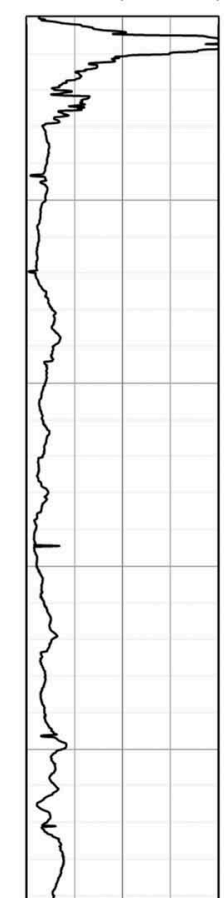

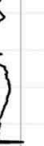
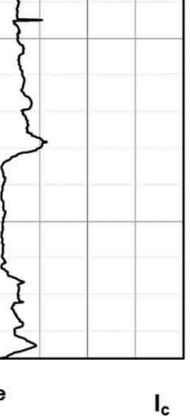

050100150200250
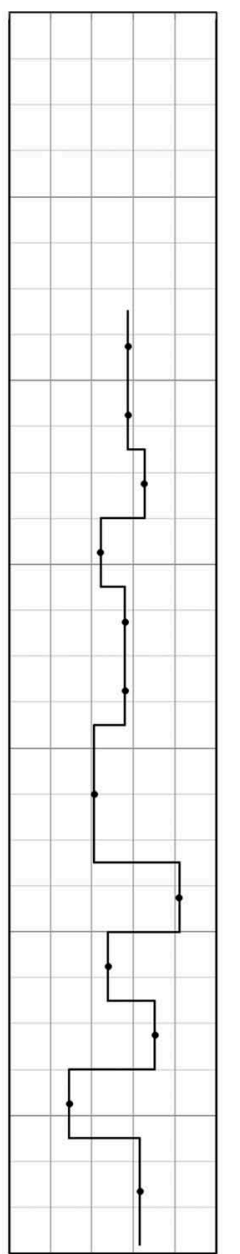

Robertson et al. (1998) Soil Type (d)

(e)
$I_{c} \quad$ Classification by 23

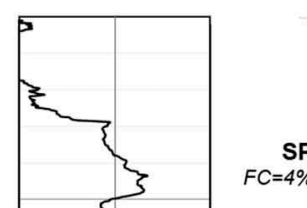

SP
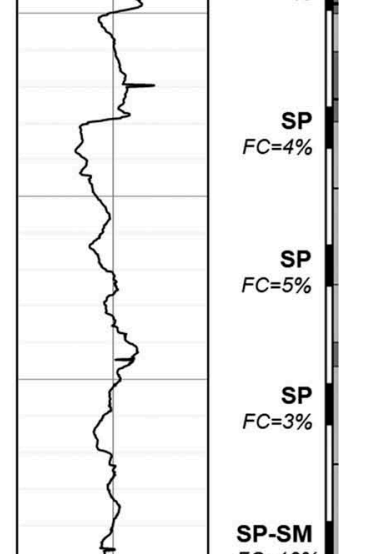

SP-SM

FC $=10 \%$

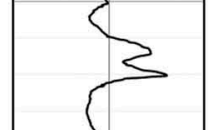

SP-SM

FC=9\%

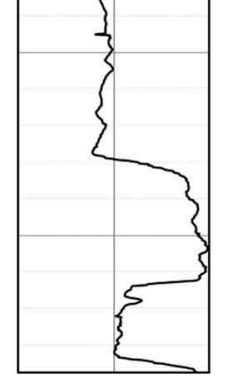

SP-SM

$F C=8 \%$

SP-SC

$F C=8 \%$

Figure 4 Example of collected and obtained data at one location, L16. (a) Measured cone penetration resistance. (b) Measured friction resistance. (c) Shear-wave velocity versus depth from SCPT test. (d) Soil behavior type index based on interpretation from CPT. (e) Soil classification based on USCS.

The soil stratigraphy was also accomplished by using the chart that linked measured cone parameters to soil-type. Robertson and Wride [1998] stated equations to determine the normalized cone penetration resistance, $q_{\mathrm{c} 1 N}$, and standardized friction ratio, $F_{\mathrm{r}}$ : 


$$
\begin{gathered}
\mathrm{q}_{\mathrm{c} 1 \mathrm{~N}}=\left(\frac{\mathrm{q}_{\mathrm{c}}}{\mathrm{P}_{\mathrm{a}}}\right)\left(\frac{\mathrm{P}_{\mathrm{a}}}{\sigma_{\mathrm{vo}}{ }^{\prime}}\right)^{\mathrm{n}} \\
\mathrm{F}_{\mathrm{r}}=\left[\frac{\mathrm{f}_{\mathrm{s}}}{\mathrm{q}_{\mathrm{c}}-\sigma_{\mathrm{vo}}}\right] 100 \%
\end{gathered}
$$

where $P_{\mathrm{a}}$ is the atmospheric pressure, $s_{\mathrm{vo}}$ ' is the effective vertical stress in the same units as $P_{\mathrm{a}}, s_{\mathrm{vo}}$ is the total vertical stress, and $n$ is the stress exponent. The $n$ values were estimated from the non-dimensional soil behavior type index, $I_{\mathrm{c}}$, and $s_{\mathrm{vo}}$ ' by using the relationship given by [Robertson 2009]

$$
\mathrm{n}=0.381\left(\mathrm{I}_{\mathrm{c}}\right)+0.05 \frac{\sigma_{\text {vo }}^{\prime}}{\mathrm{P}_{\mathrm{a}}}-0.15
$$

where $I_{\mathrm{c}}$ values were estimated from the normalized cone penetration resistance and friction resistance by using the empirical relationship given by [Robertson and Wride 1998]

$$
\mathrm{I}_{\mathrm{c}}=\left[\left(3.47-\log \mathrm{q}_{\mathrm{cl}}\right)^{2}+\left(\log \mathrm{F}_{\mathrm{r}}+1.22\right)^{2}\right]^{0.5}
$$

where $q_{\mathrm{c} 1}$ is the normalized cone penetration resistance with the stress exponent of 1.0. To exemplify, Fig. 4d-e illustrate the comparison of soil classification based on the interpretation from the CPTu and USCS. By using the USCS, the soil type in the borehole classified as SP, SP-SM, and SP-SC with FC determined $<11 \%$ in eight different depths up to $13.5 \mathrm{~m}$. Based on CPT-based soil type, from depths 1.5 to $11.5 \mathrm{~m}$, the borehole composed of soil with the behavior of clean sand to silty sand $\left(1.61 \leq I_{c} \leq 2.24\right)$, which related reasonably well to USCS-classification. However, from depth 11.5 to $12.5 \mathrm{~m}$ the CPT-based soil behavior predicted a more clay-like behavior, such as clayey silt to silty clay $\left(2.61 \leq I_{c} \leq 2.95\right)$ which was different from USCS-classification. The side-by-side comparison at any of the test sites revealed that the CPT-based soil behavior type did not always agree with traditional USCS-based soil types in the mixed soils region. The CPTbased soil type can predict if the soil behavior is controlled mainly by clay or sand, since the cone responds to the in-situ mechanical behavior of the soil and not directly to soil classification criteria based only on grain-size distribution and plasticity carried out on disturbed sample [Robertson, 2009]. Based on CPT-based soil type, the full experiment site composed of soil with the behavior of clean to silty sand $\left(1.44 \leq I_{c} \leq 2.05\right)$, silty sand to sandy silt $\left(2.05 \leq I_{c} \leq 2.60\right)$, with relatively small interbedded layers with the behavior of clayey silts to silty clays $\left(2.60 \leq I_{\mathrm{c}} \leq 2.95\right)$ and clay to silty clay $\left(2.95 \leq I_{\mathrm{c}} \leq 3.56\right)$.

Soils have the same geological age (Holocene-age) and geological depositional environments (uncemented deposits). The age and bonding of the soil was identified using an empirical parameter, $K_{\mathrm{G}}$, suggested by Schneider and Moss [2011]:

$$
\mathrm{K}_{\mathrm{G}}=\left(\frac{\mathrm{G}_{\mathrm{o}}}{\mathrm{q}_{\mathrm{t}}}\right)\left(\mathrm{q}_{\mathrm{c} 1 \mathrm{~N}}\right)^{0.75}
$$

where $G_{\mathrm{o}}$ is small strain shear modulus in the same unit as $q_{\mathrm{t}}$. The tip resistance of the cone was corrected for the effect of pore water pressure acting behind the cone tip due to the unequal area affect [Lunne et al., 1997]: 


$$
\mathrm{q}_{\mathrm{t}}=\mathrm{q}_{\mathrm{c}}-\mathrm{u}_{2}(1-\mathrm{a})
$$

where $u_{2}$ is the pore water pressure above the cone face and $a$ is the cone area ratio, which is approximately equal to the ratio of cross-sectional area of the load cell to the projected area of the cone. The cone used in this study had a cone ratio of 0.9 . The water level at the field test area was measured by using the observation wells and penetration-induced pore water pressure data obtained by the CPTu. In general, the depth of the ground water table at the study area varied from 1 to $3 \mathrm{~m}$ below the ground surface. Schneider and Moss [2011] showed that Holocene-aged sandy soils with no bonding tend to have values between 110 and 330 , with a median value of $215 . K_{\mathrm{G}}$ values in the tested area fall within the range of 35 to 350 with an average of 165.

\subsection{Shear-Wave Velocity}

Following the CPTu tests, SCPTs were performed, based on ASTM D5778-12 standards, at $1.5 \mathrm{~m}$ apart from the corresponding SPT holes. A major advantage of field measurements of $V_{\mathrm{s}}$ is that the soil is tested in its natural state, thus mitigating the dramatic effects of sample disturbance caused by drilling, tube insertion, extraction, transportation, storage, trimming, and reconsolidation. The SCPT is the modification of the CPTu test that allows measurement of $V_{\mathrm{s}}$ in a downhole testing arrangement [Campanella et al., 1986]. Within SCPT tests, it is also possible to measure $q c, f s$, and $u_{2}$ for each $1 \mathrm{~cm}$ of penetration. However, during each seismic test, the penetration of the cone was stopped, and this particular time gap had the potential to influence the measured $q c, f_{s}$, and $u_{2}$ values. Therefore, only shear-wave velocities were obtained from the SCPTs.

The seismic rod used in the SCPT test was attached to the classic CPTu probe that housed a triaxial accelerometer. As shown in Fig. 5a, the seismic cone pushed into the soil, and penetration was stopped at desired depths of about $0.75 \mathrm{~m}$ intervals. An L-shaped steel plate was placed on the ground surface $1.5 \mathrm{~m}$ apart from the SCPTu hole. The horizontal shear waves that were generated by striking the plate laterally with a sledgehammer traveled through the soil and reached the triaxial accelerometer. The dynamic signal processing and filtering of the signals were done by using the Seismic Analysis Program.

Before the analysis, filtering of signals was required to clarify the signals and to remove the effects of unwanted noise such as the wind, traffic, and electricity distribution networks. Often these are high-frequency signals. Alternatively, seismic sources on ground surface-generated noise are low frequency. In this study, "spectral analysis" function was used for filtering seismic signals. This feature changes the signals that are in the amplitude-time domain into the magnitude-frequency domain and allowed us to realize the natural frequencies of noises. Using the band-pass type of filter, we removed all signals that have a frequency higher than a high-pass limit and all frequencies lower than the lowpass limit.

After the data filtering, the analysis of filtered signals was done with the cross-correlation method. The cross correlation of impact signals at depth intervals of $0.75 \mathrm{~m}$ was determined by shifting the lower signal above the upper signal in steps equal to the time interval between the digitized points of the signal. The time shift $(\Delta t)$ giving the greatest sum was taken as the time shift interval used to calculate the $V_{\mathrm{s}}$ [Campanella and Stewart, 1992]. As an example, 

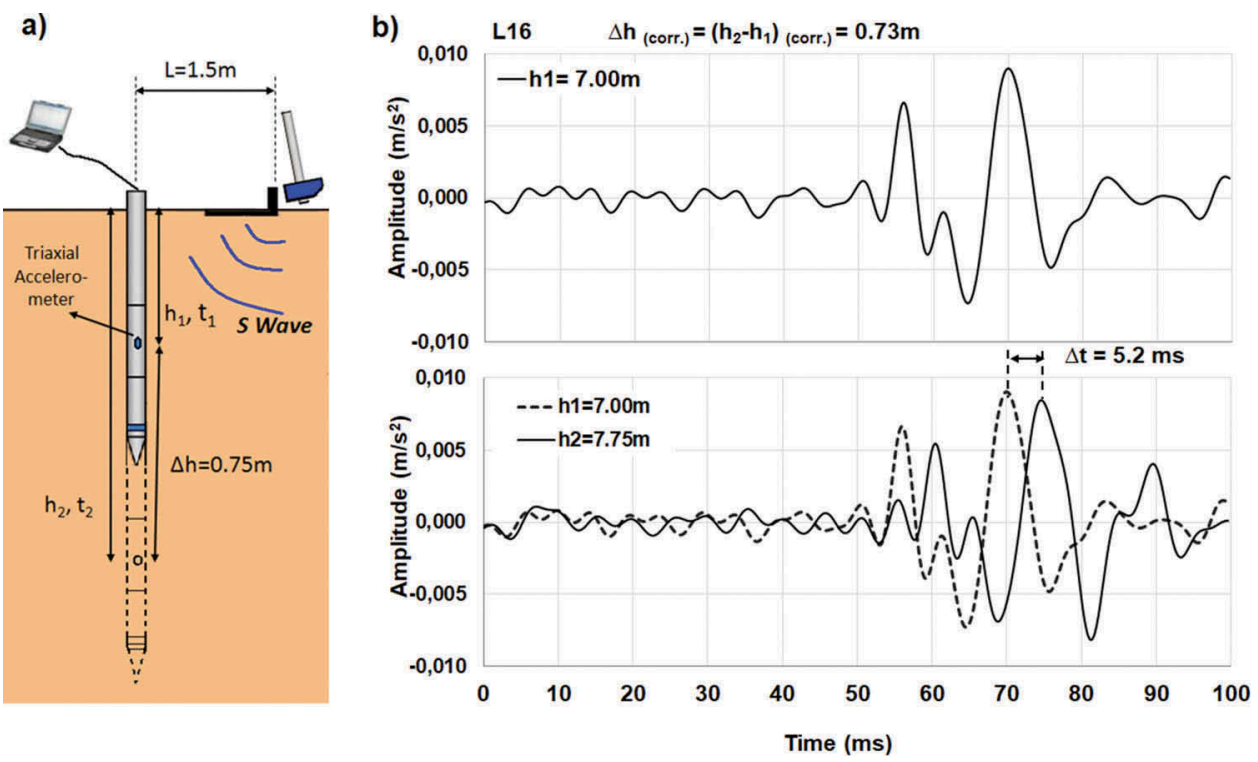

Figure 5 (a) Schematic representation of seismic cone penetration test in the field. (b) Cross-correlation method for time interval at location L16.

the cross-correlation method to find the time interval at location L16 is presented in Fig. $5 \mathrm{~b}$. The digitized points of signals were at 7.00 and $7.75 \mathrm{~m}$. The altered distance between two recordings was determined as $0.73 \mathrm{~m}$. Time shifting of the signals at two different depths was $5.2 \mathrm{~ms}$. The $V_{\mathrm{s}}$ between 7 and $7.75 \mathrm{~m}$ was calculated to be $140 \mathrm{~m} / \mathrm{s}$.

Total $115 V_{\mathrm{s}}$ data were measured in the Holocene-age deposits where $V_{\mathrm{s}}$ values varied from about $50 \mathrm{~m} / \mathrm{s}$ to $210 \mathrm{~m} / \mathrm{s}$. Andrus et al. [2007] showed that most Holocene-age deposits have $V_{\mathrm{s}}$ values $<250 \mathrm{~m} / \mathrm{s}$. To exemplify, Fig. $4 \mathrm{c}$ displays the $V_{\mathrm{s}}$ profile obtained from location L16, where the minimum and maximum $V_{s}$ values obtained about 73-206 m/s. In natural deposits, the $V_{\mathrm{s}}$ is usually controlled by the number and area of particle contacts. The number and area of grain to grain contacts depends on relative density, effective stress state, rearrangement of particles with time, and cementation. Therefore, both geological age, soil-type, and stiffness of the soil other than depth and fines often control the variation of $V_{\mathrm{s}}$ in the natural deposits. The soils in the site have similar geological age (Holocene-age), geological depositional environments, and bonding (unbounded soils). In general, the increase in $V_{\mathrm{s}}$ was observed with an increase in cone penetration resistance. However, the unique relation was not detected between $V_{\mathrm{s}}$ and cone penetration resistance at the same FC and depth. Holzer et al. [2005] studied several different natural deposits and showed that $V_{\mathrm{s}}$ increases with depth only in the mud, which also displayed an increasing stiffness with depth. Furthermore, Kokusho et al. [1995] measured $V_{\mathrm{s}}$ as low as $60-90 \mathrm{~m} / \mathrm{s}$ at gravely soils in Mori town in Hokkaido. Similar to the vertical effective stress correction used for penetration resistance, the measured $V_{\mathrm{s}}$ in the field were normalized by the following equation [Sykora, 1987; Robertson et al., 1992]:

$$
\mathrm{V}_{\mathrm{s} 1}=\mathrm{V}_{\mathrm{s}}\left(\frac{\mathrm{P}_{\mathrm{a}}}{\sigma_{\mathrm{vo}}{ }^{\prime}}\right)^{0.25}
$$


where $P_{\mathrm{a}}$ is the atmospheric pressure, $P_{\mathrm{a}}$ and $\sigma_{\mathrm{v} 0}$ are in $\mathrm{kPa}$, and $V_{\mathrm{s} 1}$ and $V_{\mathrm{s}}$ are in $\mathrm{m} / \mathrm{s}$. This equation assumes a constant coefficient of earth pressure at rest, $K_{\mathrm{o}}$, for all soil types [Andrus and Stokoe, 2000]. Once normalized for the effect of the overburden pressure, the $V_{\mathrm{s}}$ values are therefore likely to essentially reflect the soil-type and stiffness of granular soils.

\section{Establishment of CRR- $V_{s 1}$ Correlation Based on Fines Content}

\subsection{Effect of Fines on CPT- $V_{s 1}$ Correlations}

The effect of fines on cone penetration resistance is strong [Ecemis and Karaman, 2014]. However, to date, the contribution of fines on the $V_{\mathrm{s}}$ has been studied less completely and not well understood. In the literature, many correlations have been proposed between cone penetration resistance and $V_{\mathrm{s}}$ for different soils. The contribution of fines on the $q_{\mathrm{c} 1 N^{-}} V_{\mathrm{s} 1}$ correlations is questionable because some of the suggested relationships use rather simple approximations of the $q_{\mathrm{c} 1 N}-V_{\mathrm{s} 1}$ trend over a wide range of soil types. Therefore, first, a more close examination is needed to estimate the effect of fines on the $q_{\mathrm{c} 1 N^{-}} V_{\mathrm{s} 1}$ correlation. In this study, for the soils that have the same geological age (Holocene-age) and geological depositional environments (uncemented deposits), overburden stress corrected $V_{\mathrm{s}}$ values with normalized cone penetration resistance for three distinct ranges of non-/low plastic FC by mass of FC $\leq 5 \%, 5 \%<\mathrm{FC} \leq 20 \%$, and $20 \%<$ $\mathrm{FC} \leq 35 \%$, are shown in Fig. $6 \mathrm{a}-\mathrm{c}$. Figure 7 presents how the FC, cone penetration resistance, and $V_{\mathrm{s}}$ were selected at the same depths. FC obtained from a $30 \mathrm{~cm}$ long soil sample from the SPT spoon. Cone penetration resistance data measured within $30 \mathrm{~cm}$ depth were averaged to find the average cone penetration resistance. The recorded impact signals at depth intervals of $0.75 \mathrm{~m}$ were cross-correlated to find the $V_{\mathrm{s}}$ within $0.75 \mathrm{~m}$ depth.

As shown in Fig. 6a-b, a total of 84 disturbed soil samples collected between 0 and $20 \%$ FC, and the majority of the field measured $V_{\mathrm{s} 1}$ values range from $60 \mathrm{~m} / \mathrm{s}$ to $200 \mathrm{~m} / \mathrm{s}$. Figure $6 \mathrm{c}$ presents 23 disturbed soil samples collected from $20 \%$ to $35 \%$ FC and measured $V_{\mathrm{s} 1}$ values range from 96 to $210 \mathrm{~m} / \mathrm{s}$. For the same $q_{\mathrm{c} 1 N}$, at each FC range, the measured $V_{\text {s1 }}$ show significant scatter. This can be due to the variation in soil-type [Zhou et al., 2010], distribution of particle size and gradation [Kokusho, 2007; Karray et al., 2011] of the tested soil in the field. In each figure, a region is determined in which all the measured $V_{\mathrm{s} 1}$ values with the corresponding $q_{\mathrm{c} 1 N}$ are located. These regions are bounded by different solid black curves which represent the upper and lower limit $V_{\mathrm{s} 1}\left(V_{\mathrm{s} 1 \text {-upper limit }}\right.$ and $V_{\mathrm{s} 1-}$ lower limit $)$ values with $q_{\mathrm{c} 1 N}$ for three distinct ranges of non-/low plastic FC. The limit $V_{\mathrm{s} 1}$ values for all three ranges increase with increasing $q_{\mathrm{c} 1 N}$. For all given FC ranges $(0-35 \%)$, a change in normalized cone penetration resistance from 5 to 30 increased the $V_{\text {s1-upper limit }}$

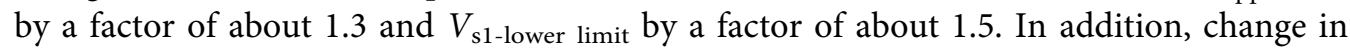
normalized cone penetration resistance from 30 to 60 increased the $V_{\text {s1-lower limit }}$ and $V_{\text {s1- }}$ upper limit of silty sands, containing fines from 0 to $35 \%$, by a factor of about 1.2 . Moreover, for all FC ranges, a change in normalized cone penetration resistance from 60 to 90 increased the $V_{\text {s1-lower limit }}$ and $V_{\text {s1-upper limit }}$ by a factor of about 1.1. The increase in $V_{\mathrm{s}}$ of clean sand $(\mathrm{FC} \leq 5 \%)$ determined in this study is also compatible with the estimated increase in the $V_{\mathrm{s}}$ given by Idriss and Boulanger [2008]. Based on the studies of Idriss 


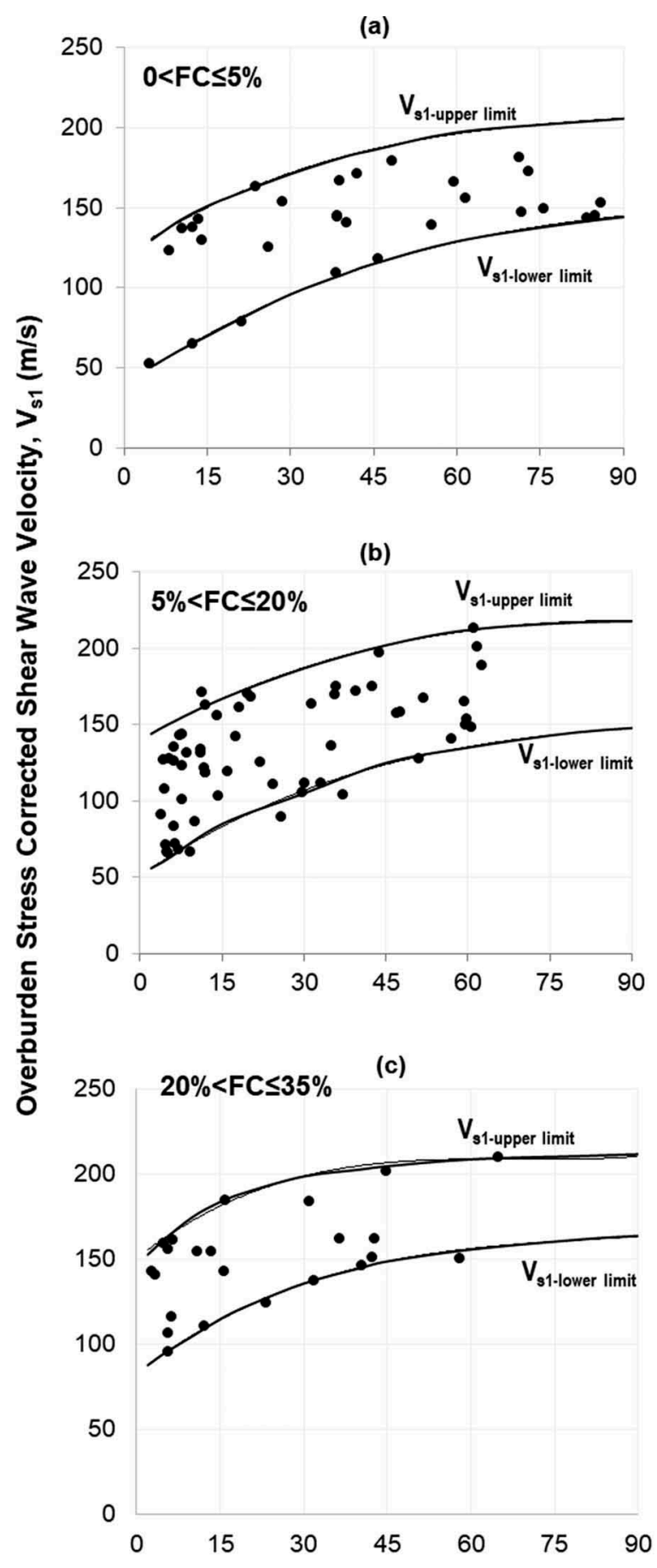

Normalized Cone Penetration Resistance, $q_{c 1 N}$

Figure 6 The change of the overburden stress-corrected shear-wave velocity with normalized cone penetration resistance at three different ranges of fines content (a) $5 \% \geq \mathrm{FC}$, (b) $20 \% \geq \mathrm{FC}>5 \%$, and (c) $35 \% \geq \mathrm{FC}>20 \%$. 

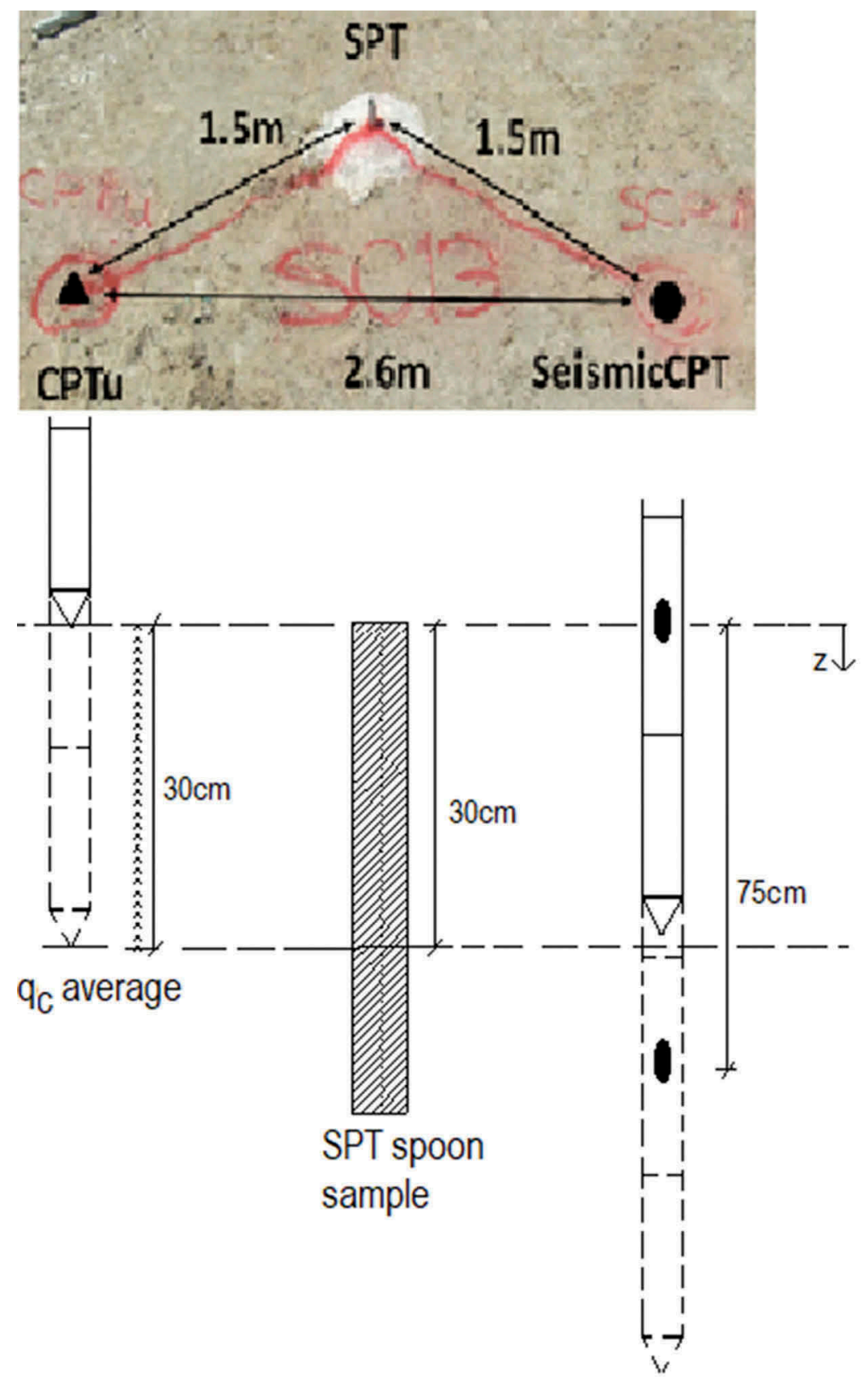

Shear wave velocity

Figure 7 An illustration of SPT spoon sample and cone penetration test data points with corresponding depths of shear-wave velocity. 
and Boulanger [2008], the relative density of clean sand from 30 to $80 \%$ expected to increase the $V_{\mathrm{s}}$ by a factor of 1.4 .

To compare the effect of fines on $V_{\mathrm{s}}$, the variation of $V_{\mathrm{s} 1 \text {-lower limit }} /\left(V_{\mathrm{s} 1 \text {-lower limit }}\right)_{\mathrm{FC} \leq 5 \%}$ and $V_{\text {s1-upper limit }} /\left(V_{\text {s1-upper limit }}\right)_{\mathrm{FC} \leq 5 \%}$ obtained from the figures mentioned above are

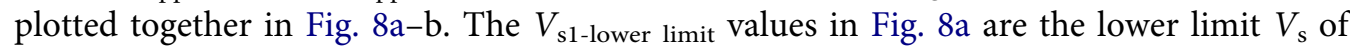
sand with different $\mathrm{FC}$ and $\left(V_{\mathrm{s} 1 \text {-lower limit }}\right)_{\mathrm{FC} \leq 5 \%}$ values represent the lower limit $V_{\mathrm{s}}$ of clean sands. The $V_{\text {s1-lower limit }}$ and $\left(V_{\text {s1-lower limit }}\right)_{\mathrm{FC} \leq 5 \%}$ were compared at the same normalized cone penetration resistance. This figure illustrates that for the $q_{\mathrm{c} 1 N}$ values from 15 to 30, $V_{\text {s1-lower limit }}$ increased by an average factor of 1.5 with an increase in FC from $5 \%$ to $30 \%$. For the $q_{\mathrm{c} 1 N}$ values from 30 to 100 , as FC increased up to $15 \%$, the $V_{\text {s1-lower limit }}$ increased by an average factor of 1.05. In addition, beyond FC of about $15 \%, V_{\text {s1-lower limit }}$ increased by an average factor of 1.3 with further increase in FC up to about $30 \%$.

The $V_{\text {s1-upper limit }}$ values in Fig. $8 \mathrm{~b}$ are the upper limit $V_{\mathrm{s}}$ of sand with different FC and $\left(V_{\text {s1-upper limit }}\right)_{\mathrm{FC} \leq 5 \%}$ represents the top limit $V_{\mathrm{s}}$ of clean sands. The $V_{\text {s1-upper limit }}$ and $\left(V_{\text {s1- }}\right.$ upper limit $)_{\mathrm{FC} \leq 5 \%}$ were compared at the same normalized cone penetration resistance. This figure clearly illustrates that at each $q_{\mathrm{c} 1 N}$, as FC increased up to $15 \%$, the $V_{\text {s1-upper limit }}$ slightly increased by an average factor of 1.1. However, for the $q_{\mathrm{c} 1 \mathrm{~N}}$ values up to about 30 , $V_{\text {s1-upper limit }}$ increased by an average factor of 1.1 as FC increased from $15 \%$ to $30 \%$. For the $q_{\mathrm{c} 1 N}$ values $>30$, the change in $V_{\text {s1-upper limit }}$ was not observed.

These findings show that there is a little difference between $V_{\mathrm{s}}$ measurements of sand and silty or clayey sand. Hence, fines effect on $V_{\mathrm{s}}$ is weak. The limited number of laboratory test conducted by researchers [Iwasaki and Tatsuoka, 1997; Salgado et al., 2000; Paydar and Ahmadi, 2016] reported that at the same void ratio, $V_{\mathrm{s}}$ slightly decreases with an increase in FC up to about $15 \%$. For the same $q_{\mathrm{c} 1 N}$, the estimated decrease in the $V_{\mathrm{s}}$ with an increase in FC up to about $15 \%$ is not compatible with the small increase in limit $V_{\mathrm{s} 1}$ determined in this study.

(a)

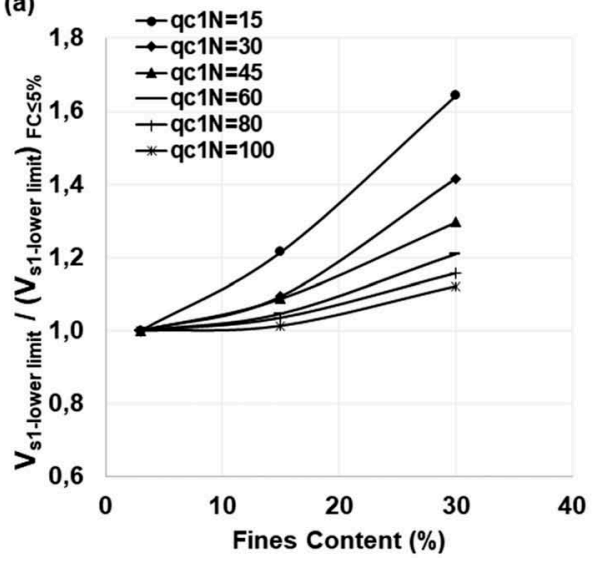

(b)

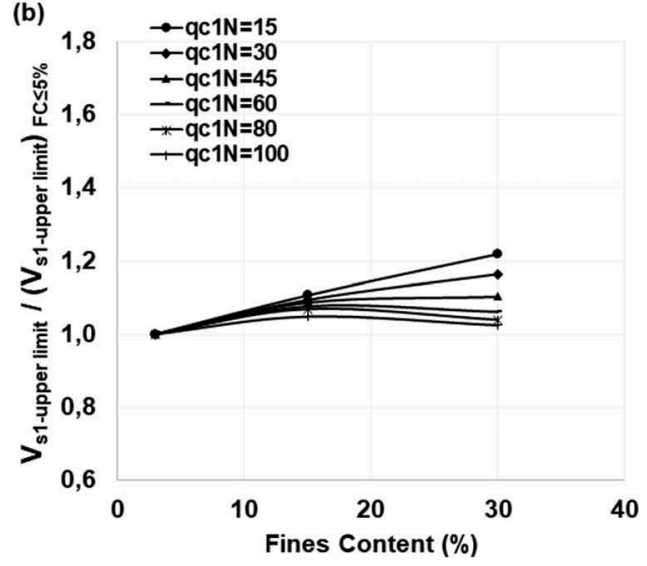

Figure 8 Summary of the effects of fines content and $q_{\mathrm{c} 1 N}$ on the overburden corrected shear-wave velocity. 


\subsection{Effect of Fines on $C R R-V_{s 1}$ Correlation}

In this study, the effect of fines on liquefaction resistance is quantified at different shearwave velocities by combining the effects of fines and cone penetration resistance on $V_{\text {s1- }}$ lower limit and $V_{\text {sl-upper limit }}$ (Fig. 6a-c) and the current field-based CPT-liquefaction assessment method [Robertson and Wride, 1998]. CPT-based criteria of Robertson and Wride [1998] show that the fines effect on the CRR $-q_{\mathrm{c} 1 N}$ relationship is strong. This is due to the effect of fines that cause partially drained conditions (slow rate of dissipation of excess pore pressures) during penetration leading to a significant decrease in CPT resistance [Ecemis and Karaman, 2014].

Figure 9 illustrates the corresponding liquefaction resistance values with upper and lower limit $V_{\mathrm{s} 1}$ for three distinct ranges of non-/low plastic FC of FC $\leq 5 \%, 5 \%<\mathrm{FC} \leq$ $20 \%$, and $20 \%<\mathrm{FC} \leq 35 \%$. As shown in the figure, the liquefaction resistance- $V_{\text {s1-upper }}$ limit curves from $0 \%$ to $35 \%$ non-/low plastic FC are close to each other. This is likewise true for CRR- $V_{\text {s1-lower limit }}$ curves. Huang et al. [2005] also indicated that there is no need to distinguish the CRR $-V_{\mathrm{s} 1}$ correlation according to the FC. For the same FC range and $V_{s}$, the reason to obtain different liquefaction resistance may be due to the differences in the soil types.

Comprehensive research in the literature was also performed to obtain CRR- $V_{\mathrm{s} 1}$ curves on different types of sands and silty sands [e.g., Tokimatsu et al., 1986; Robertson et al., 1992; Lodge, 1994; Andrus and Stokoe, 2000; Roy, 2005; Zhou and Chen, 2007; Baxter et al., 2008; Zhou et al., 2010; Kayen et al., 2013; and Ahmadi and Paydar, 2014]. The CRR- $V_{\text {s1 }}$ curves proposed by above-given researchers for clean sandy soils $(\mathrm{FC}<5 \%)$ and sands containing different amount of fines $(5 \%<\mathrm{FC} \leq 20 \%$, and $20 \%<\mathrm{FC} \leq 35 \%$ ), with the established limit curves developed in this study, are shown in Fig. 10.

Tokimatsu et al. [1986] and Baxter et al. [2008] proposed laboratory-based CRR- $V_{\text {s1 }}$ correlations for Niigata sand and Providence sand, respectively. Robertson et al. [1992] and Lodge [1994] suggested a CRR- $V_{\mathrm{s} 1}$ curve based on the field performance observations. Roy [2005] proposed a CRR- $V_{s 1}$ curve based on the direct measurement of $V_{\mathrm{s}}$ at soils with $\mathrm{FC}<5 \%$ and observations of liquefaction after the Chi-Chi earthquake. Kayen et al. [2013] suggested CRR- $V_{\text {s1 }}$ curves that are based on the probability of liquefaction $\left(\mathrm{P}_{\mathrm{L}}\right)$ contours from $5 \%$ to $95 \%$. They collected data from a large number of liquefaction case histories that are composed of very young (Holocene-age) silica-based soils that have no bonding. For $V_{\mathrm{s} 1}$-based initial liquefaction evaluations, they recommend to use the $\mathrm{P}_{\mathrm{L}}$ contour of $15 \%$. Zhou and Chen [2007] and Zhou et al. [2010] performed laboratory investigations to develop a lower bound (liquefaction boundary) $V_{\mathrm{s}}$-based liquefaction resistance correlations for different types of sands (FC $\leq 5 \%$ and $5<\mathrm{FC}<35 \%)$ and silty sands $(\mathrm{FC} \geq 35 \%)$, respectively. Ahmadi and Paydar [2014] performed laboratory tests and plotted CRR- $V_{\mathrm{s} 1}$ curves of Babolsar sand and Firoozkooh sand.

The curves recommended by NCEER [Andrus and Stokoe, 2000] are also plotted in Fig. 10. As mentioned earlier in Section 1, these curves are widely used in practice for evaluation of liquefaction resistance based on $V_{\mathrm{s}}$ for Holocene-age, uncemented sands with fines from 0 to $35 \%$. In this method, liquefaction resistance can be approximated and expressed by the following equation [Andrus and Stokoe, 2000]: 


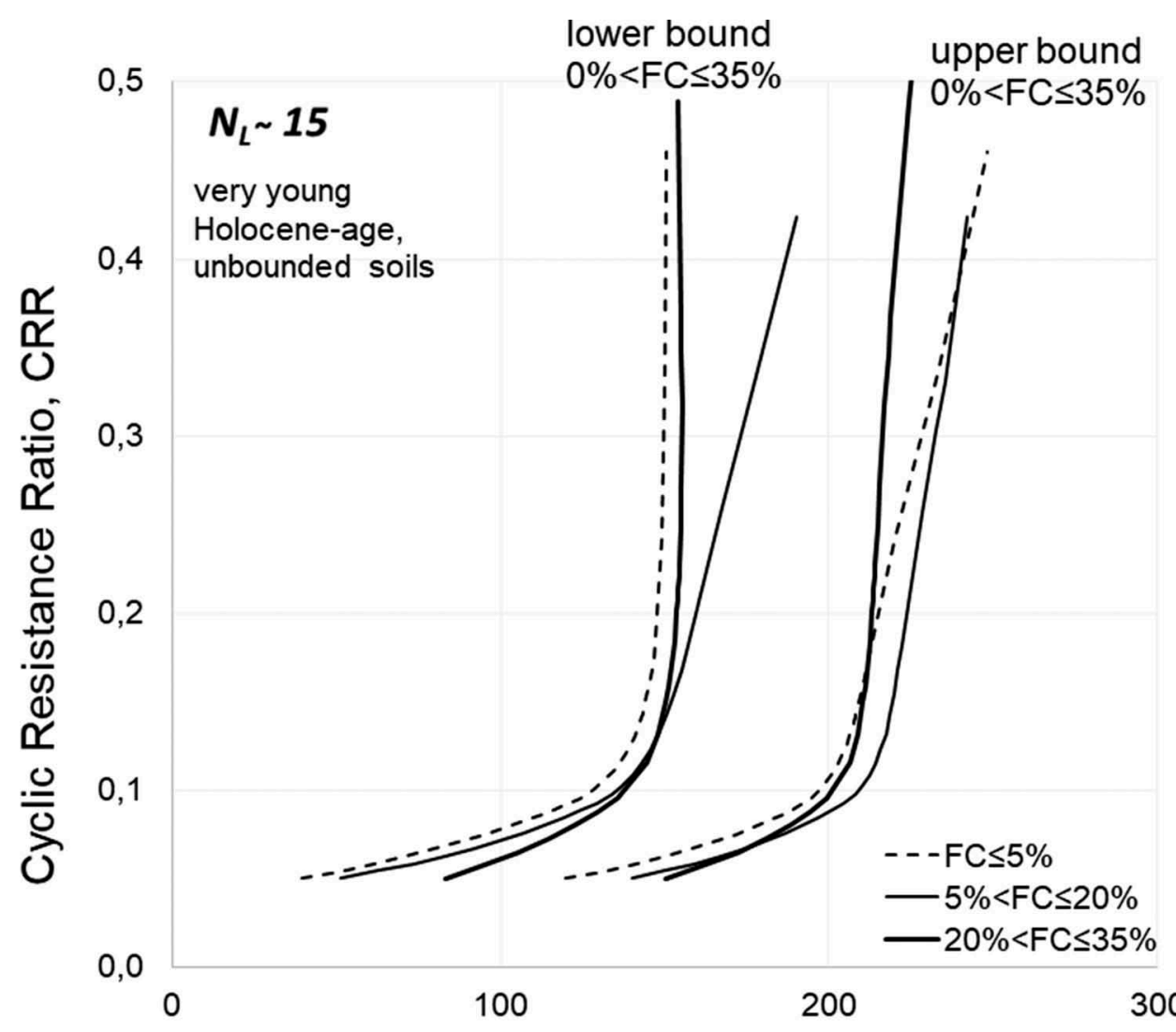

\section{Overburden Stress Corrected Shear Wave Velocity, $\mathrm{V}_{\mathrm{s} 1}, \mathrm{~m} / \mathrm{s}$}

Figure 9 Proposed lower bound and upper bound liquefaction resistance (estimated from the CPTbased criteria for liquefaction assessment of Robertson and Wride, 1998) versus measured $V_{s 1}$ correlation curves for fines content from $0 \%$ to $35 \%$.

$$
\mathrm{CRR}=0.022\left(\frac{\mathrm{V}_{\mathrm{s} 1}}{100}\right)^{2}+2.8\left(\frac{1}{\mathrm{~V}_{\mathrm{s} 1}{ }^{*}-\mathrm{V}_{\mathrm{s} 1}}-\frac{1}{\mathrm{~V}_{\mathrm{s} 1}{ }^{*}}\right)
$$

where CRR corresponds to 7.5 magnitude earthquake of about 15 cycles [Finnie and Randolph, 1994; Green and Terri, 2005]. $V_{\mathrm{s} 1}{ }^{*}$ is the limiting upper value of $V_{\mathrm{s} 1}$ for soil liquefaction occurrence. Cyclic stress ratio values above about 0.35 are limited in the case history data gathered by Andrus and Stokoe [2000]. Therefore, estimates of $V_{\mathrm{s} 1}{ }^{*}$ rely on penetration $-V_{\mathrm{s}}$ correlation which created a paucity of $V_{\mathrm{s}}$ data in the CSR region above approximately 0.35 and for $V_{\mathrm{s} 1}$ greater than about $215 \mathrm{~m} / \mathrm{s}$. For $\mathrm{FC} \leq 5 \% V_{\mathrm{s} 1}{ }^{*}=215 \mathrm{~m} / \mathrm{s}$, for $5 \%<\mathrm{FC}<35 \% V_{\mathrm{s} 1}{ }^{\star}=215-0.5(\mathrm{FC}-5) \mathrm{m} / \mathrm{s}$, for $\mathrm{FC} \geq 35 V_{\mathrm{s} 1}{ }^{*}=200 \mathrm{~m} / \mathrm{s}$.

As shown in the figure, the correlations between CRR and $V_{s 1}$ are not unique; there is a significant scattering of the curves for different soil types. In addition, all the existing CRR- $V_{\mathrm{s} 1}$ curves are located between the lower and upper bound region determined in this study. These findings show that although the existing methods can be used as an initial 


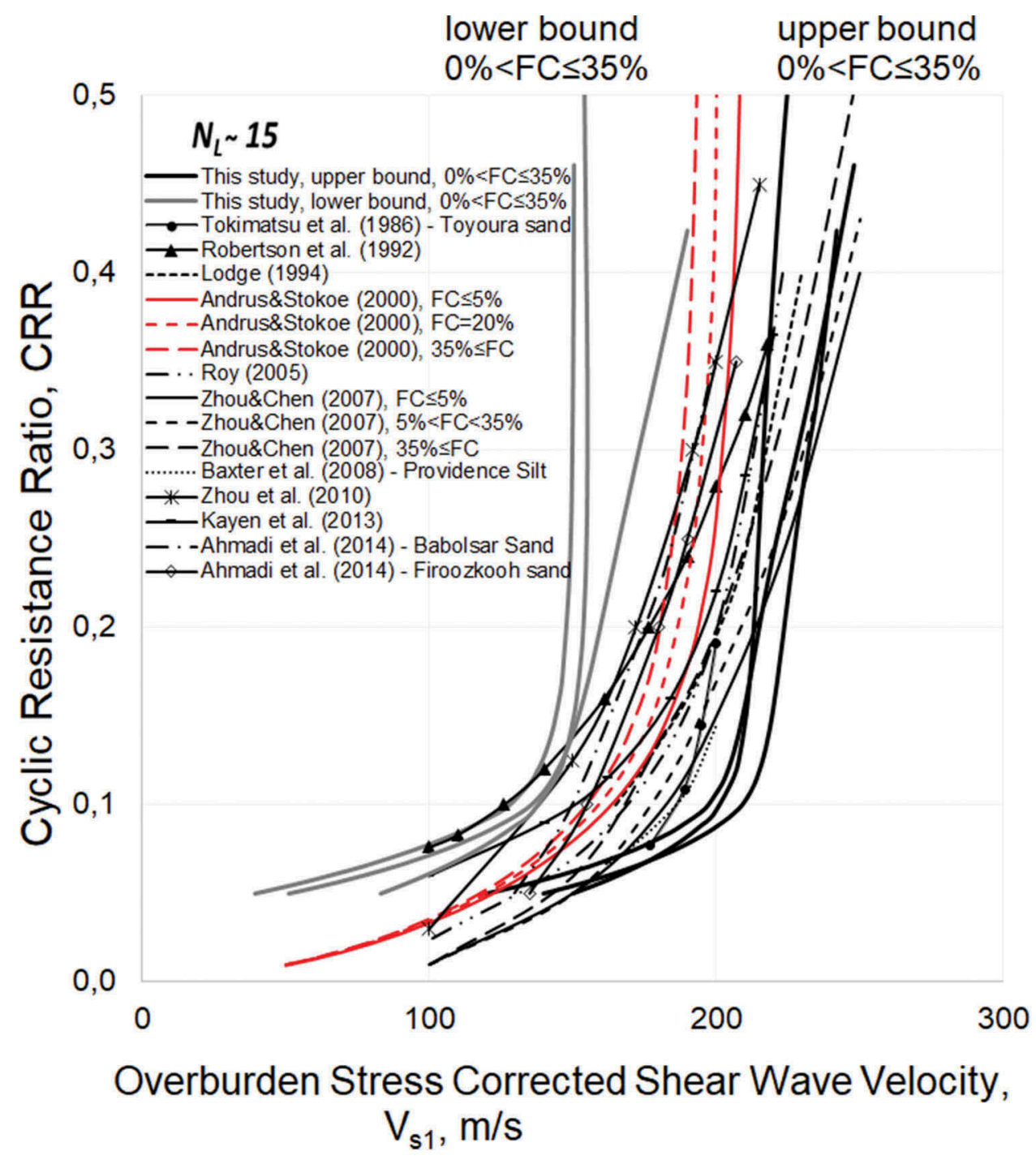

Figure 10 Comparison of existing $V_{\mathrm{s} 1}$-based liquefaction assessment curves with the lower and upper bound liquefaction resistance findings of this study.

estimation of liquefaction resistance, it may underestimate or overestimate the liquefaction resistance of different types of soils. Furthermore, Youd et al. [2001] also indicated that the simplified charts should be used with engineering judgment and caution. Accordingly, successful application of these charts to other soils requires an understanding of the phenomenon observed, its limitations, and possible modifications needed to it to be applied successfully to a different type of soil. For a more accurate assessment of the liquefaction resistance, there is a clear need for a soil-specific CRR- $V_{\mathrm{s} 1}$ correlation. 


\section{Establishment of CRR- $V_{s 1}$ Correlation Based on Soil Type}

\subsection{Effect of Soil-Type on CPT- $V_{s 1}$ Correlations}

The CPT-based soil type is a better indicator of soil behavior than the soil classification criteria based only on grain-size distribution and soil plasticity since the cone responds to the in-situ mechanical behavior of the soil [Robertson, 2009]. In this study, the CPT-based soil behavior type index, $I_{\mathfrak{c}}$, modified by Robertson and Wride [1998] is used to determine the soil-type. In the experiment site, values of $I_{c}$ range from 1.44 to 3.56. As shown in Fig. 11, for $I_{\mathrm{c}}$ values between 1.44 and 2.05 (clean to silty sand), a region is determined in which 28 measured $V_{\mathrm{s} 1}$ values with the corresponding $q_{\mathrm{c} 1 N}$ are located. The data in this region is plotted by circle symbols and bounded by the solid black curves which represent the $I_{c}$ values of 1.44 and 2.05. For $I_{c}$ values between 2.05 and 2.59 (silty sand to sandy silt), a region is determined in which 39 measured $V_{\mathrm{s} 1}$ values with the corresponding $q_{\mathrm{c} 1 \mathrm{~N}}$ are located. The data in this region is plotted by triangle symbols and bounded by the solid black curves which represent the $I_{\mathrm{c}}$ values of 2.05 and 2.59. For $I_{\mathrm{c}}$ values between 2.59 and 3.56 (clayey silts to silty clay), a region is determined in which 48 measured $V_{\text {s1 }}$ values with the corresponding $q_{\mathrm{c} 1 N}$ are located. The data in this region are plotted by square symbols and bounded by the solid black curves which represent the $I_{\mathfrak{c}}$ values of 2.59 and 3.56. Therefore, for soil behavior type index of 1.44, 2.05, 2.60, and 3.56 four curves were recommended for predicting the overburden stress corrected $V_{\mathrm{s}}$. A generalized relationship for the soils that have the similar geological age (Holocene-age), geological depositional environments, and bonding (unbounded soils), the relationship between $V_{\mathrm{s} 1}$ and $q_{\mathrm{c} 1 N}$ is proposed as follows:

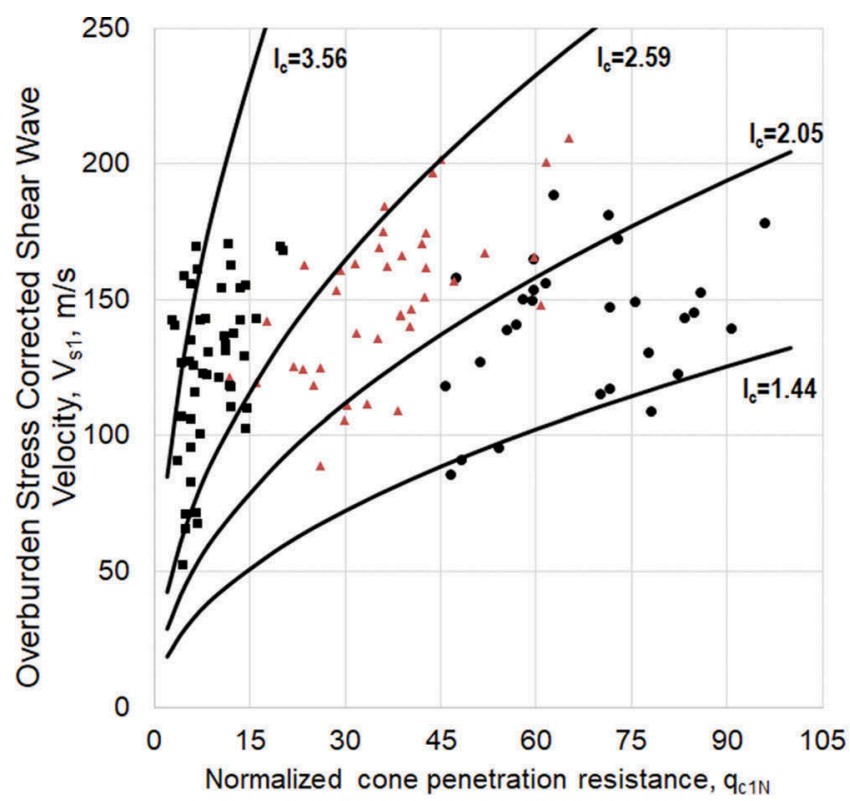

Figure 11 At four different soil-behavior-type index, the change of the $V_{\mathrm{s} 1}$ with $q_{\mathrm{c} 1 N}$ for the very young Holocene-age, unbounded soils. 


$$
\mathrm{V}_{\mathrm{s} 1}=\sqrt{10^{0.62 \mathrm{I}_{\mathrm{c}}+1.35} \mathrm{q}_{\mathrm{c} 1 \mathrm{~N}}}
$$

$I_{\mathrm{c}}$ is determined irrespective of FC of the soil and $V_{\mathrm{s} 1}$ in $\mathrm{m} / \mathrm{s}$. In the past years, several regression equations have been proposed between cone penetration resistance and $V_{\mathrm{s}}$ for different soils. A summary of some of these empirical correlations proposed at different locations for different soil types is presented in Table 1. It should be noted that almost all of the existing empirical relationships listed in Table 1 use a power-law relationship between $V_{\mathrm{s}}$ and $q_{\mathrm{c} 1 N}$ and based on statistical regression analysis of datasets which typically contain a significant amount of scatter in the measured data.

These valuable empirical relations are plotted in Fig. 12a-b with the proposed curves in this study. Such correlations are significantly different from each other due to the different soil mineralogy, geological age, cementation and effective stress state [Andrus et al., 2004]. For example, McGann et al. [2015] showed that existing correlations for predicting $V_{\mathrm{s}}$

Table 1 Previous correlations between $q_{\mathrm{c} 1 \mathrm{~N}}$ and $V_{\mathrm{s} 1}$.

\begin{tabular}{|c|c|c|}
\hline Reference & Correlation, $V_{\mathrm{s} 1}(\mathrm{~m} / \mathrm{s})$ & Soil type \\
\hline Baldi et al. [1989] & $10_{\mathrm{qc} 1 N}^{0.13}$ & Freshly deposited silica sand \\
\hline Rix and Stokoe [1991] & $123_{\mathrm{q} c 1 N}{ }^{0.125}$ & $\begin{array}{l}\text { Freshly deposited poorly graded sand and silty sand with FC } \\
\text { ranging from } 1 \% \text { to } 14 \%\end{array}$ \\
\hline Robertson et al. [1992] & $60.3_{\mathrm{qc} 1 N}^{0.23}$ & Young, uncemented silica clean sand \\
\hline Fear and Robertson [1995] & $79.5_{\mathrm{qc} 1 N}^{0.23}$ & $\begin{array}{l}\text { Sand contained about } 30 \% \text { fines and large amount of } \\
\text { carbonate shell material }\end{array}$ \\
\hline Hegazy and Mayne [1995] & $72.8_{\mathrm{qc} 1 N^{0.192}}^{0.221}$ & Holocene sand \\
\hline Andrus et al. [2004] & $62.6(\mathrm{qc1N})_{\mathrm{cs}}^{0.231}$ & Holocene-age-unbounded sand deposits with $\mathrm{FC}<20 \%$ \\
\hline Andrus et al. [2007] & $16.5_{\mathrm{qc} 1 N}{ }^{0.411} / \mathrm{C}^{0.97}$ & $\begin{array}{l}\text { General soil deposits with various geological ages } \\
\text { (Holocene, Pleistocene, and Tertiary ages) }\end{array}$ \\
\hline Robertson [2009] & $\left(10_{c}^{(0.551+1.68)} \mathrm{qc} 1 N\right)^{0.5}$ & Holocene and Pleistocene age-unbounded silica-based soils \\
\hline Karray et al. [2011] & $149_{\mathrm{qc1}} 0.205$ & Peribonka data (cohesive soils) qc1 in $\mathrm{MPa}$ \\
\hline Cai et al. [2014] & $38_{\mathrm{qc} 1} 0.61$ & Cohesive soils qc1 in MPa \\
\hline
\end{tabular}
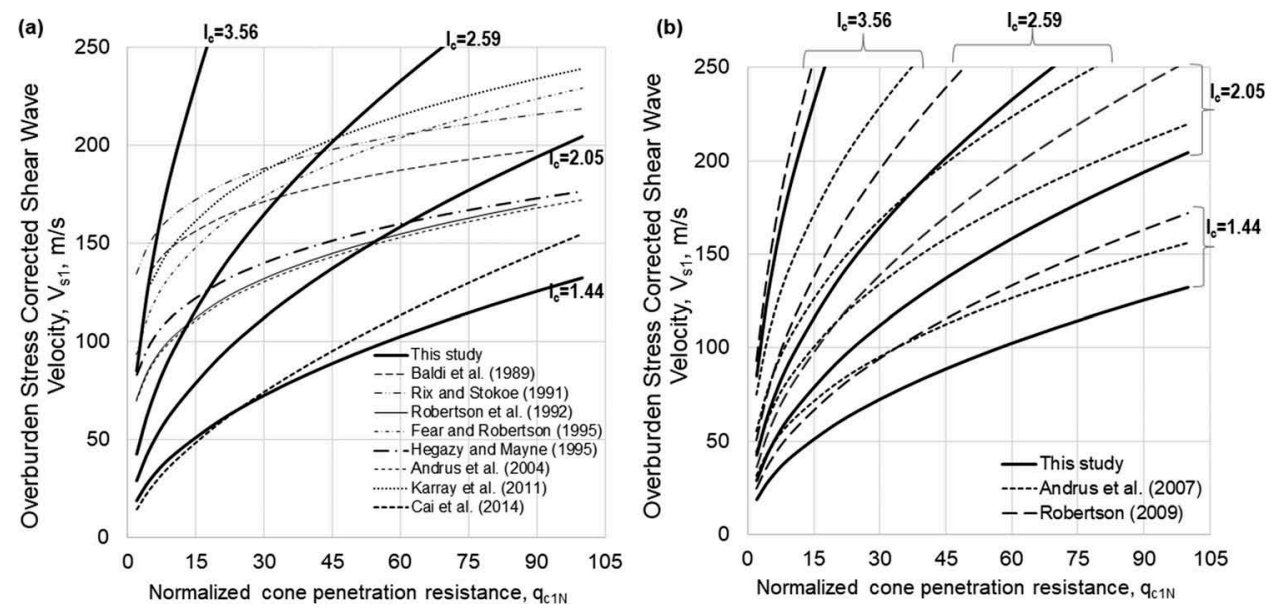

Figure 12 Comparison of the proposed CPT- $V_{s 1}$ curves with the existing relationships based on (a) different soils and (b) soil-behavior-type index, $I_{c}$. 
from CPT data overestimate the $V_{\mathrm{s}}$ of the Christchurch soil deposits. Therefore, these relationships could only be valid for the similar type of soils that are encountered in the investigated area.

Recently, Andrus et al. [2007] and Robertson [2009] developed a CPT- $V_{s}$ correlation based on soil behavior type, $I_{\mathrm{c}}$. Andrus et al. [2007] considered $V_{\mathrm{s}}$ and CPT measurements for general soil deposits with various geological ages. Age effects generally lead to an increase in $V_{\mathrm{s}}$ over time. Robertson [2009] developed a CPT- $V_{\mathrm{s}}$ correlation based on Holocene-age, unbounded silica-based soil sites which are very similar to the soil-type investigated in this research. For different $I_{c}$ values, the $q_{\mathrm{c} 1 N^{-}} V_{\mathrm{s} 1}$ curves suggested by Andrus et al. [2007], and Robertson [2009] with the proposed curves in this study are compared in Fig. 12b. As shown in the figure, for $I_{c}=1.44$ and 2.05, the developed relationships in this study displays slightly below the other relationships. For $I_{c}=2.59$, the curve suggested by Andrus et al. [2007] coincides with the curve developed in this study. For $I_{c}=3.56$, the correlation of Robertson [2009] matches with the data represented in this study.

\subsection{Effect of Soil Type on $C R R-V_{s 1}$ Correlation}

Recently, Baxter et al. [2008], Zhou et al. [2010], and Ahmadi and Paydar [2014] showed that the $V_{\mathrm{s}}-\mathrm{CRR}$ correlation could not be unique for different types of sands. In this study, the CPT-based CRR- $V_{\text {s1 }}$ relationships are developed by combining the effects of soil type and cone penetration resistance on $V_{\mathrm{s} 1}$ (Equation 9) and the current field-based CPTliquefaction assessment method [Robertson and Wride, 1998] as follows:

$$
\begin{gathered}
\mathrm{CRR}=0.833\left[\frac{\mathrm{V}_{\mathrm{s1}}^{2} \mathrm{~K}_{\mathrm{c}}}{10^{0.62 \mathrm{I}_{\mathrm{c}}+4.35}}\right]+0.05 \text { for } K_{c} q_{c 1 N}<50 \\
\mathrm{CRR}=93\left[\frac{\mathrm{V}_{\mathrm{s1}}^{2} \mathrm{~K}_{\mathrm{c}}}{10^{0.62 \mathrm{I}_{\mathrm{c}}+4.35}}\right]^{3}+0.08 \text { for } 50<K_{c} q_{c 1 N}<160
\end{gathered}
$$

where CRR corresponds to 7.5 magnitude earthquake of about 15 cycles. The use of proposed correlations is limited to the unbounded, very young soil mostly $<3,000$ years old. For clean sand $\left(I_{c} \leq 1.64\right)$, Robertson and Wride [1998] suggested using 1.0 for FC correction factor $\left(K_{c}\right)$. However, in this study, for clean sand $K_{c}$ value of 1.0 is found somewhat conservative. Therefore, $K_{\mathrm{c}}$ is assumed 0.44 for $I_{\mathrm{c}} \leq 1.64$.

The CPT-liquefaction assessment method, proposed by Robertson and Wride [1998], was applied for soil behavior type index $<2.6$. Therefore, the corresponding liquefaction resistance values with $V_{\mathrm{s} 1}$ for three different soil types of 1.44, 2.05 and 2.59 are displayed in Fig. 13 with different solid curves. As shown in the figure, for three different soil types, the liquefaction resistance up to around $0.08, \mathrm{CRR}-V_{\mathrm{s} 1}$ curves are almost same. For the same $V_{s}$, CRR increase with an increase in soil-type.

The CRR- $V_{\mathrm{s} 1}$ curves developed for different $I_{\mathrm{c}}$ are compared with the curves proposed by Tokimatsu et al. [1986], Robertson et al. [1992], Lodge [1994], Andrus and Stokoe [2000], Roy [2005], Zhou and Chen [2007], Baxter et al. [2008], Zhou et al. [2010], Kayen et al. [2013], and Ahmadi and Paydar [2014] on different types of sands and silty sands. Figure 14 compares these $V_{\mathrm{s} 1}$-based curves with the equivalent CPT-based liquefaction triggering curves derived in this study for $I_{c}$ of 1.44-2.59. The figure illustrates that the 


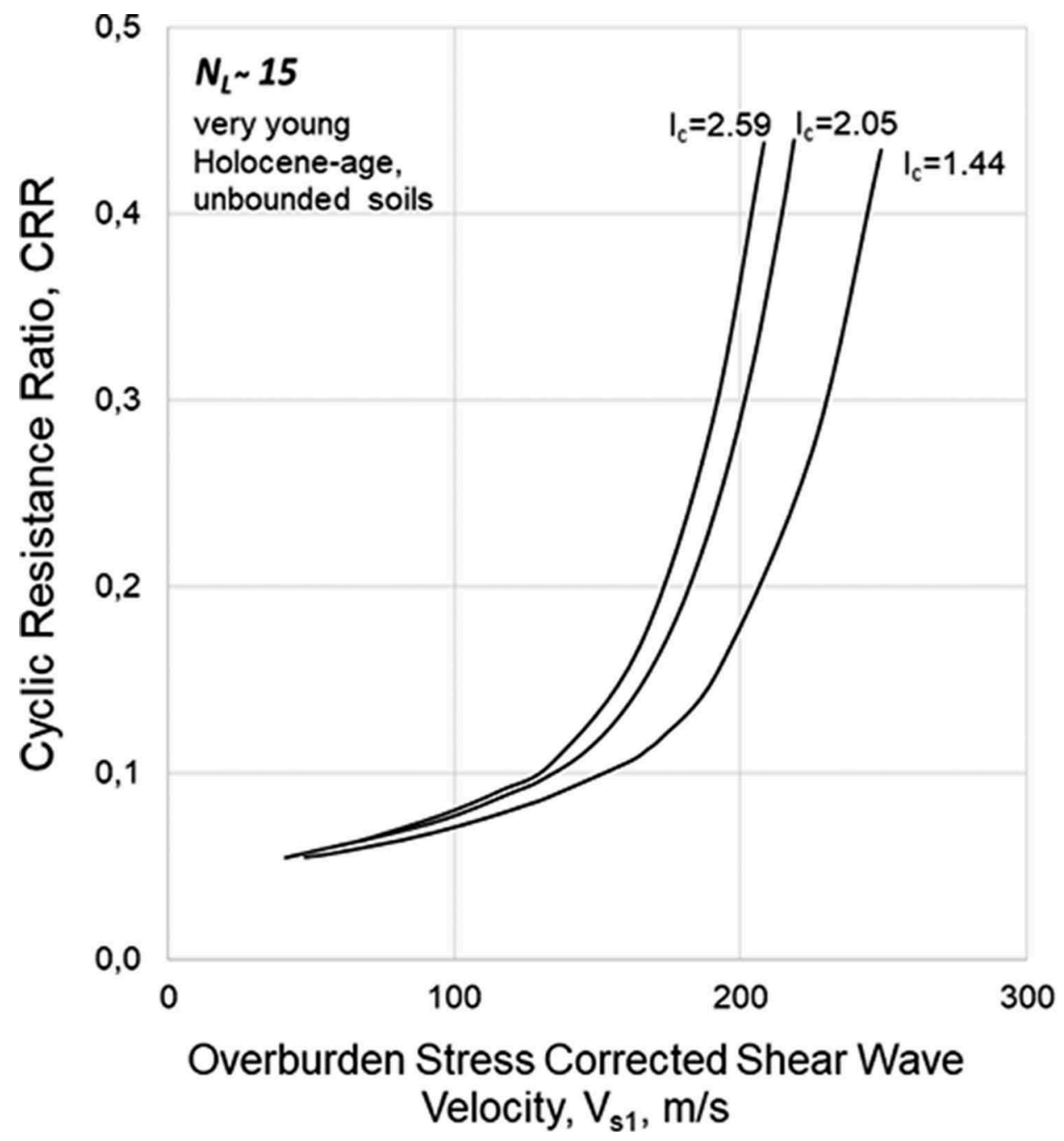

Figure 13 Proposed cyclic resistance ratio (estimated from the CPT-based criteria for liquefaction assessment of Robertson and Wride, 1998) versus $V_{s 1}$ correlation curves for three soil-behavior-type index, $I_{c}$.

$V_{\mathrm{s} 1}$-based curves for Holocene-age soils fall within the proposed curves of 1.44-2.59. Based on the suggested values by Fear and Robertson [1995]; soil type of 1.44-2.59 represents the FC of 2-35\%, respectively. These findings show that soils of similar geological age, geological depositional environments, and bonding, the correlation between $V_{\mathrm{s} 1}$ and CRR can be quantified at different soil behavior type rather than the FC of the soil.

\section{Summary and Conclusion}

In this study, $115 V_{\mathrm{s}}$ and $13 \mathrm{CPT}$ profiles obtained in an experiment site constituted an important data bank to investigate the effects of non-/low plastic fines and soil-type on CPT-based CRR- $V_{\text {s1 }}$ relationship. The following conclusions were drawn from this study: 


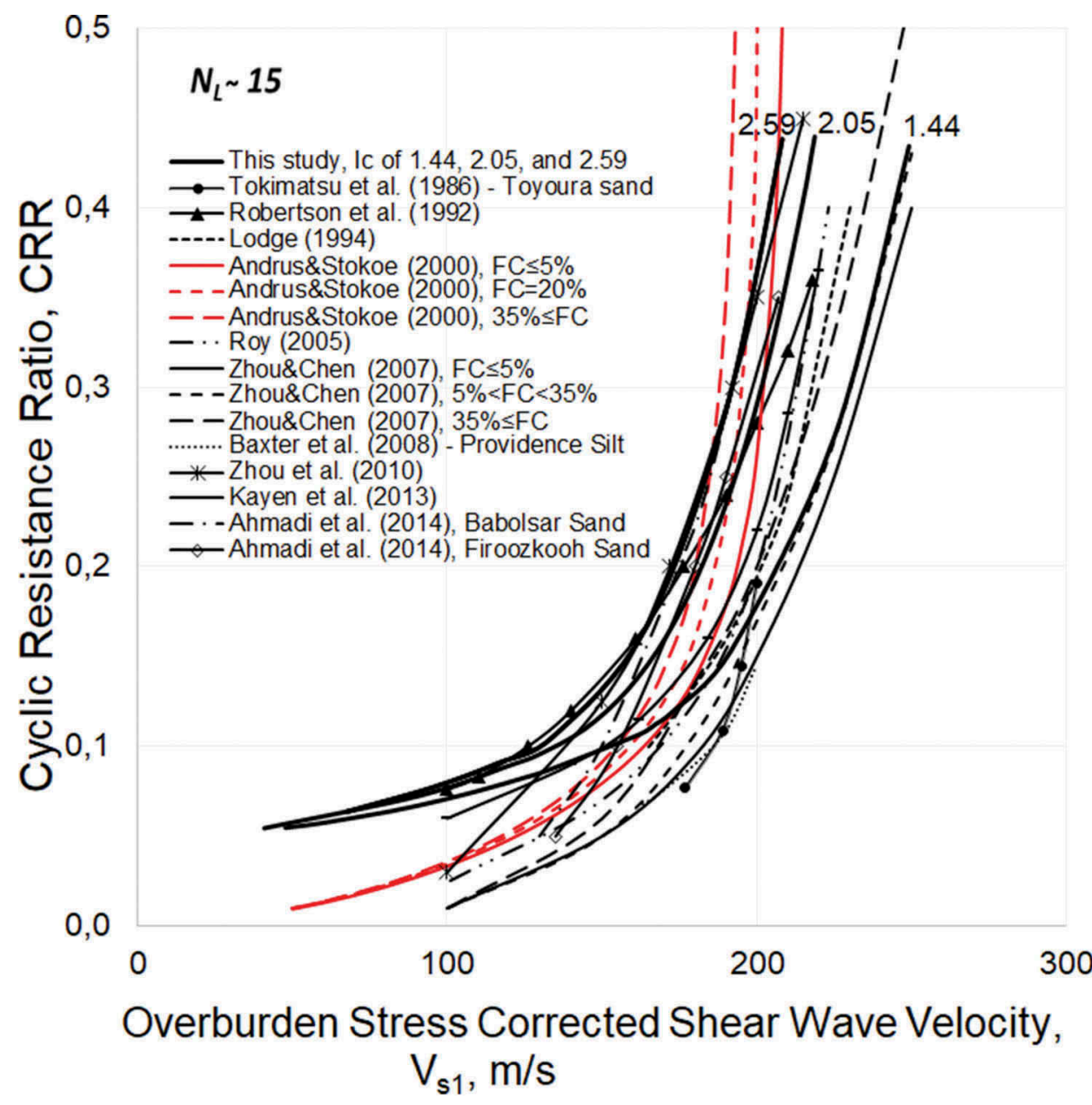

Figure 14 Comparison of CRR- $V_{s 1}$ curves from this study and those from existing curves for different soils.

(1) The changing trends of $V_{\mathrm{s} 1}$ according to $q_{\mathrm{c} 1 N}$ were established for different FC. At each FC range, for the same $q_{\mathrm{c} 1 N}$, the significant scatter of the measured $V_{\mathrm{s} 1}$ data was due to the variation in particle gradation and soil-type. The upper and lower limit $V_{\mathrm{s} 1}$ values at different FC range compared to observe the effect of fines on $V_{\mathrm{s} 1}$. A slight difference observed between $V_{\mathrm{s}}$ measurements of sand and silty or clayey sand. Hence, fines effect on $V_{s}$ is not strong.

(2) The liquefaction resistance with upper and lower limit $V_{s 1}$ are obtained for the liquefaction resistance representing the CPT-based criteria of Robertson and Wride [1998] in terms of $V_{\text {s1 }}$ for three distinct ranges of non-/low plastic FC of FC $\leq 5 \%, 5 \%<\mathrm{FC} \leq 20 \%$, and $20 \%<\mathrm{FC} \leq 35 \%$. The upper bound CRR $-V_{\text {s1 }}$ curves from $0 \%$ to $35 \%$ non-/low plastic FC are close to each other. The same is true for lower bound CRR- $V_{\mathrm{s} 1}$ curves. For soils of similar geological origin, age, FC range and $V_{\mathrm{s}}$, 
the reason to obtain different liquefaction resistance may be due to the differences in the soil types.

(3) The reinterpreted liquefaction resistance at the different $V_{\mathrm{s} 1}$ and FC range is compared with the existing CRR- $V_{s 1}$ curves on different types of sands and silty sands. For the same FC, the existing CRR $-V_{\mathrm{s} 1}$ correlations are not unique; there is a significant scattering of the curves for different soil types. However, existing CRR$V_{\text {s1 }}$ curves are located between the lower and upper bound region determined in this study. This shows that although the proposed methods can be used as an initial estimation of liquefaction resistance, they may underestimate or overestimate the liquefaction resistance of different types of soils.

(4) The changing trends of $V_{\mathrm{s} 1}$ according to $q_{\mathrm{c} 1 N}$ were established for different soil types of the tested soil in the field. We proposed a soil-type dependent $V_{\mathrm{s} 1}-q_{\mathrm{c} 1 N}$ relationship for the soils that have the similar geological age (Holocene-age mostly $<3,000$ years old), geological depositional environments, and bonding (unbounded soils). The new equation is particularly useful when it is not feasible to measure $V_{s}$ at all desired locations. However, geological age, as well as cementation need to be considered when predicting $V_{s}$ from cone measurements.

(5) The CPT-based CRR $-V_{s 1}$ correlation is suggested to be used in engineering practice by combining the effects of soil-type and cone penetration resistance on $V_{s 1}$ and the current field-based CPT-liquefaction assessment method [Robertson and Wride, 1998]. For the same $V_{s}$, CRR increase with an increase in soil-type. The CRR- $V_{s 1}$ curves developed for different $I_{\mathrm{c}}$ is compared with the existing CRR- $V_{\mathrm{s} 1}$ curves on different types of sands and silty sands. $V_{s 1}$-based curves for Holocene-age soils fall within the proposed curves of 1.44 to 2.59 . These findings show that, for a more accurate assessment of the liquefaction resistance, there is a clear need for a soil specific CRR- $V_{s 1}$ correlations.

It is important to note that the correlation between $V_{\mathrm{s} 1}$ and CRR can be quantified at different soil-type rather than the FC of the soil. In practice, the geotechnical engineer should choose between the less-accurate estimation of CRR from $V_{\mathrm{s} 1}$ based on FC and the more-accurate estimation of CRR from $V_{\mathrm{s} 1}$ based on soil type. The choice, of course, would depend on the risk and economic aspects of the project.

\section{Funding}

This work was supported by the Scientific and Technological Research Council of TurkeyTUBITAK [grant number 110M602] and European Union Commission, 7th framework program Marie Skłodowska-Curie fellowship [grant number PIRG05-GA-2009-248218].

\section{References}

Ahmadi, M. M. and Paydar, N. A. [2014] "Requirements for soil-specific correlation between shear wave velocity and liquefaction resistance of sands", Soil Dynamics and Earthquake Engineering 57, 152-163. doi:10.1016/j.soildyn.2013.11.001

Andrus, R., Mohanan, N., Piratheepan, P., Ellis, B. and Holzer, T. [2007] "Predicting shear-wave velocity from cone penetration resistance," Proceedings of the Fourth International Conference on Earthquake Geotechnical Engineering, Thessaloniki, Greece. Paper no.1454. 
Andrus, R. D., Piratheepan, P., Ellis, B. S., Zhang, J. and Juang, C. H. [2004] "Comparing liquefaction evaluation methods using penetration- $\mathrm{V}_{\mathrm{s}}$ relationships", Soil Dynamics and Earthquake Engineering 24(9), 713-721. doi:10.1016/j.soildyn.2004.06.001

Andrus, R. D. and Stokoe, K. H. [2000] "Liquefaction resistance of soils from shear-wave velocity", Journal of Geotechnical and Geoenvironmental Engineering 126(11), 1015-1025. doi:10.1061/ (ASCE) 1090-0241(2000)126:11(1015)

Baldi, G., Belloti, R., Ghionna, V., Jamiolkowski, M. and LoPresti, D. [1989] "Modulus of sands from CPT sand DMTs," Proceedings of the 12th International Conference on Soil Mechanic Sand Foundation Engineering 1, 165-170.

Baxter, C. D. P., Bradshaw, A. S., Green, R. A. and Wang, J. [2008] "Correlation between cyclic resistance and shear-wave velocity for providence silts", Journal of Geotechnical and Geoenvironmental Engineering 134(1), 37-46. doi:10.1061/(ASCE)1090-0241(2008)134:1(37)

Cai, G. J., Puppala, A. J. and Liu, S. Y. [2014] "Characterization on the correlation between shear wave velocity and piezocone tip resistance of Jiangsu clays", Engineering Geology 171, 96-103. doi:10.1016/j.enggeo.2013.12.012

Campanella, R. G., Robertson, P. K. and Gillespie, D. [1986] "Seismic cone penetration test, use of in situ tests in geotechnical engineering", in GSP 6 (ASCE, Blacksburg, VA), pp. 116-130.

Campanella, R. G. and Stewart, W. P. [1992] "Seismic cone analysis using digital signal processing for dynamic site characterization", Canadian Geotechnical Journal 29, 477-486. doi:10.1139/t92-052

De Alba, P., Benoit, J., Pass, D. G. and Carter, J. J. [1994] "Low strain shear modulus by indirect metods," 13th International Conference on Soil Mechanics And Foundation Engineering 1, 173-176.

Ecemis, N. [2013] "Effects of consolidation characteristics on CPT cone resistance and liquefaction resistance in silty soils", in The Scientific and Technological Research Council of TurkeyTUBITAK, Project No: 110M602 (TUBITAK, Ankara, Turkey).

Ecemis, N. [2014] "Effects of permeability and compressibility on liquefaction assessment of silty soils using cone penetration resistance", in European Union 7th Framework Program Marie Curie Fellowship, Grant No: PIRG05-GA-2009-248218 (European Union Commission, Brussels, Belgium).

Ecemis, N. and Karaman, M. [2014] "Influence of non-/low plastic fines on cone penetration and liquefaction resistance”, Engineering Geology 181, 48-57. doi:10.1016/j.enggeo.2014.08.012

El-Sekelly, W., Abdoun, T. and Dobry, R. [2016] "Liquefaction resistance of a silty sand deposit subjected to preshaking followed by extensive liquefaction", Journal of Geotechnical and Geoenvironmental Engineering 142(4), 04015101. doi:10.1061/(ASCE)GT.1943-5606.0001444

Fear, C. E. and Robertson, P. K. [1995] "Estimating the undrained strength of sand: a theoretical framework", Canadian Geotechnical Journal 32(5), 859-870. doi:10.1139/t95-082

Finnie, I. M. S. and Randolph, M. F. [1994] "Punch-through and liquefaction induced failure of shallow foundations on calcareous sediments," Proceedings of the Int. Conf. On Behavior of Offshore Structures, Boston, pp. 217-230.

Green, R. A. and Terri, G. A. [2005] "Number of equivalent cycles concept for liquefaction evaluations--revisited", Journal of Geotechnical and Geoenvironmental Engineering 131(4), 477-488. doi:10.1061/(ASCE)1090-0241(2005)131:4(477)

Hegazy, Y. and Mayne, P. [1995] "Statistical correlations between $V_{s}$ and cone penetration data for different soil types," Proceedings of the CPT'95, vol.2. Swedish Geotechnical Society, 173-178.

Holzer, T. L., Bennett, M. J., Noce, T. E. and Tinsley, J. C., III. [2005] "Shear-wave velocity of surficial geologic sediments in Northern California: statistical distributions and depth dependence", Earthquake Spectra 21(1), 161-177. doi:10.1193/1.1852561

Huang, A. B., Huang, Y. T. and Ho, F. J. [2005] "Assessment of liquefaction potential for a silty sand in central western Taiwan," Proc., 16th Int. Conf. on Soil Mechanics and Geotechnical Engineering, Millpress Science Publishers, Rotterdam, pp. 2653-2658.

Idriss, I. M. and Boulanger, R. W. [2008] Soil Liquefaction during Earthquakes, MNO-12, Earthquake Engineering Research Institute, Oakland, California.

Iwasaki, T. and Tatsuoka, F. [1997] "Effects of grain size and grading on dynamic shear moduli of sands", Soils and Foundations 17(3), 9-35. 
Juang, C. H., Jiang, T. and Andrus, R. D. [2002] "Assessing probability based methods for liquefaction evaluation", Journal of Geotechnical and Geoenvironmental Engineering 128(7), 580-589. doi:10.1061/(ASCE)1090-0241(2002)128:7(580)

Karray, M., Lefebvre, G., Ethier, Y. and Bigras, A. [2011] "Influence of particle size on the correlation between shear wave velocity and cone tip resistance", Canadian Geotechnical Journal 48(4), 599-615. doi:10.1139/t10-092

Kayen, R. R., Moss, R. E. S., Thompson, E. R., Seed, R. B., Cetin, K. O., Derkiureghian, A., Tanaka, Y. and Tokimatsu, K. [2013] "Shear wave velocity-based probabilistic and deterministic assessment of seismic soil liquefaction potential", Journal of Geotechnical and Geoenvironmental Engineering 139(3), 407-419. doi:10.1061/(ASCE)GT.1943-5606.0000743

Kokusho, T. [2007] "Liquefaction strengths of poorly graded and well-graded granular soils investigated by lab tests", in Earthquake Geotechnical Engineering (Springer, Dordrecht), vol. 6, pp. 159-184. doi:10.1007/978-1-4020-5893-6_8

Kokusho, T., Tanaka, Y., Kawai, T., Kudo, K., Suzuki, K., Tohda, S. and Abe, S. [1995] "Case study of rock debris avalanche gravel liquefied during 1993 Hokkaido-Nansei-Oki Earthquake”, Soils and Foundations 35(3), 83-95. doi:10.3208/sandf.35.83

Lodge, A. L. [1994] "Shear wave velocity measurements for subsurface characterization," Ph.D. thesis, Univ. of California, Berkeley, CA.

Lunne, T., Robertson, P. K. and Powell, J. J. M. [1997] Cone Penetration Testing in Geotechnical Practice, Blackie Academic, FF Spon/Routledge Publishers, NY, pp. 312.

Marchetti, S. [2010] "Sensitivity of CPT and DMT to stress history and aging in sands for liquefaction assessment," Proceedings of the CPT 2010 International Symposium, Huntington Beach, CA.

McGann, C. R., Bradley, B. A., Taylor, M. L., Wotherspoon, L. M. and Cubrinovski, M. [2015] "Development of an empirical correlation for predicting shear wave velocity of Christchurch soils from cone penetration test data", Soil Dynamics and Earthquake Engineering 75, 66-75. doi:10.1016/j.soildyn.2015.03.023

Moss, R. E. S., Seed, R. B., Kayen, R. E., Stewart, J. P., Der Kiureghian, A. and Cetin, K. O. [2006] "CPT-based probabilistic and deterministic assessment of in situ seismic soil liquefaction potential”, Journal of Geotechnical and Geoenvironmental Engineering 132(8), 1032-1051. doi:10.1061/ (ASCE)1090-0241(2006)132:8(1032)

Paydar, N. A. and Ahmadi, M. M. [2016] "Effect of fines type and content on correlation between shear wave velocity and liquefaction resistance", Geotechnical and Geological Engineering. doi:10.1007/s10706-016-9995-8

RADIUS Project [1999] Izmir deprem senaryosu ve master plani (available online at http://www. izmirbld.gov.tr/izmirdeprem/izmirrapor.htm).

Rix, G. J. and Stokoe, K. H. [1991] "Correlation of initial tangent moduli and cone penetration resistance”, in Calibration Chamber Testing, ed. A. B. Huang (Elsevier, New York) pp. 351-362.

Robertson, P. K. [2009] "Interpretation of cone penetration tests - a unified approach", Canadian Geotechnical Journal 46(11), 1337-1355. doi:10.1139/T09-065

Robertson, P. K., Woeller, D. J. and Finn, W. D. L. [1992] "Seismic cone penetration test for evaluating liquefaction potential under cyclic loading”, Canadian Geotechnical Journal 29(6), 686-695. doi:10.1139/t92-075

Robertson, P. K. and Wride, C. E. [1998] "Evaluating cyclic liquefaction potential using the cone penetration test", Canadian Geotechnical Journal 35(3), 442-459. doi:10.1139/t98-017

Roy, D. [2005] "Liquefaction susceptibility and shear wave velocity," Proc., 16th Int. Conf. on Soil Mechanics and Geotechnical Engineering, Osaka, Millpress, Rotterdam, The Netherlands, 2, pp. 435-438.

Salgado, R., Bandini, P. and Karim, A. [2000] "Shear strength and stiffness of silty sand", Journal of Geotechnical and Geoenvironmental Engineering 126(5), 451-462. doi:10.1061/(ASCE)1090-0241 (2000) 126:5(451)

Schmertmann, J. H. [1984] "Comparing DMT with CPT in NC/OC sand bucket tests", in DMT Digest No. 4, ed. GPE Inc. (GPE Inc., Gainesville, Fl, USA). 
Schneider, J. A. and Moss, R. E. S. [2011] "Linking cyclic stress and cyclic strain based methods for assessment of cyclic liquefaction triggering in sands", Geotechnical Letter 1, 31-36. doi:10.1680/ geolett.11.00021

Seed, H. B. and Idriss, I. M. [1971] "Simplified procedure for evaluating soil liquefaction potential", Journal of Soil Mechanics and Foundation Division 97(9), 1249-1273.

Seed, H. B., Idriss, I. M. and Arango, I. [1983] "Evaluation of liquefaction potential using field performance data", Journal of Geotechnical Engineering 109(3), 458-482. doi:10.1061/(ASCE) 0733-9410(1983)109:3(458)

Sykora, D. W. [1987] "Examination of existing shear wave velocity and shear modulus correlation in soils”, in Misc. Paper GL-87-22, U.S. Army Engineer Waterways Exp. Station, ed. National Government Publication (National Government Publication, Vicksburg, MS).

Tokimatsu, K. and Uchida, A. [1990] "Correlation between liquefaction resistance and shear wave velocity”, Soils Foundation 30(2), 33-42. doi:10.3208/sandf1972.30.2_33

Tokimatsu, K., Yamazako, T. and Yoshimi, Y. [1986] "Soil liquefaction evaluations by elastic shear moduli", Soils Foundation 26(1), 25-35. doi:10.3208/sandf1972.26.25

Youd, T. L., et al. [2001] "Liquefaction resistance of soils: summary report from the 1996 NCEER and 1998 NCEER/NSF workshops on evaluation of liquefaction resistance of soils", Journal of Geotechnical \& Geoenvironmental Engineering 127(10), 817-833. doi:10.1061/(ASCE)1090-0241 (2001)127:10(817)

Zhou, Y. G. and Chen, Y. M. [2007] "Laboratory investigation on assessing liquefaction resistance of sandy soils by shear wave velocity", Journal of Geotechnical and Geoenviromental Engineering 133(8), 959-967. doi:10.1061/(ASCE)1090-0241(2007)133:8(959)

Zhou, Y. G., Chen, Y. M. and Shamoto, Y. [2010] "Verification of the soil-type specific correlation between liquefaction resistance and shear-wave velocity of sand by dynamic centrifuge test", Journal of Geotechnical and Geoenviromental Engineering 136(1), 165-177. doi:10.1061/(ASCE) GT.1943-5606.0000193 